\title{
Expected Social Security Wealth Simulations And Generational Fairness of The Turkish Payg System
}

Yigit Aydede

Saint Mary'S University

Follow this and additional works at: https://ecommons.luc.edu/meea

Part of the Economics Commons

\section{Recommended Citation}

Aydede, Yigit, "Expected Social Security Wealth Simulations And Generational Fairness of The Turkish Payg System". Topics in Middle Eastern and North African Economies, electronic journal, 11, Middle East Economic Association and Loyola University Chicago, 2009, http://www.luc.edu/orgs/meea/

This Article is brought to you for free and open access by the Journals and Magazines at Loyola eCommons. It has been accepted for inclusion in Topics in Middle Eastern and North African Economies by an authorized administrator of Loyola eCommons. For more information, please contact ecommons@luc.edu. (C) 2009 the authors 
ASSA Session Number: 2

Sunday, January 4, 10:15 - 12:15 pm

Paper Prepared for the 29th ANNUAL MEETINGS OF THE MIDDLE EAST ECONOMIC ASSOCIATION

January 2-5, 2009, San Francisco, CA

in conjunction with

ANNUAL MEETINGS OF THE ALLIED SOCIAL SCIENCE ASSOCIATIONS

\section{Expected Social Security Wealth Simulations and Generational Fairness of the Turkish PAYG System}

Yigit Aydede

For additional information please contact:

Yigit Aydede

Saint Mary's University

Department of Economics

Halifax, NS B3H 3C3 Canada

yigit.aydede@smu.ca 


\begin{abstract}
As it evolves around the world, Social Security financed on pay-as-you-go (PAYG) basis increasingly becomes a Ponzi scheme due to aging populations. The main objective of Social Security is to insure seniors against an uncertain life span. However, as the probability of being a net loser rises for coming generations, this objective receives questions with increasing public confusion: how does Social Security affect lifetime wealth? How could one calculate financial terms of Social Security for households in different generations? This paper is the first attempt in the literature to calculate the aggregate social security wealth (SSW) series for an emerging country, Turkey - that has the most generous social security system in the OECD region. Our simulations cover the period between 1970 and 2003 and the results show that the anticipated SSW is the biggest part of household wealth in Turkey and therefore it should not be ignored in economic studies. In addition to the aggregate SSW series, we also analyze the generational fairness of the system by calculating its implicit rate of return for representative individuals in different age cohorts. Our principal finding is that Social Security in Turkey constitutes significant wealth transfers among different age cohorts.
\end{abstract}

Acknowledgements: We thank to Jeffery Miller and Laurence Seidman at the University of Delaware for their helpful suggestions, Can Karasikli at Bank Positive, and Gunhan Karakullukcu for their invaluable help in finding reliable data sources in Turkey. We are grateful for having the Networks Financial Institutions' support for this study.

Keywords: Household Wealth, Social Security Wealth, Intergenerational Wealth Transfers, Internal Rate of Return of PAYG.

JEL classification: J1, H55, E21 


\section{Introduction}

Social Security is the biggest portion of public budgets and affects millions of lives in many countries. Since its introduction, there has been a growing debate on its financial sustainability and effects on economic values. As it matures around the world, Social Security financed on pay-as-you-go (PAYG) basis increasingly becomes a Ponzi scheme due to aging populations. The success of parametric reforms more and more depends on the willingness of every future generation to accept decreasing lifetime wealth. The main objective of Social Security is to insure seniors against an uncertain life span. The first generations of the system were net gainers. However, as the probability of being a net loser rises for coming generations, this objective receives questions with increasing public confusion: how does Social Security affect lifetime wealth? How could one calculate financial terms of Social Security for households in different generations?

After two major economic crises in 1999 and 2001, Turkey has been undergoing the most severe recovery in its history helped by IMF and the World Bank. Following several major reforms in its fiscal policies, Turkey has become the biggest borrower (with more than $\$ 25$ billion in the last 6 years) in the history of international financial aids. What are the generational characteristics of these major reforms in Social Security and Health Care? Are these reforms able to provide a sustainable long-term recovery or do they only postpone the "disaster" to future generations? These are unanswered questions so far. The majority of proposed solutions are based on parametric adjustments in the system, perhaps because of their political feasibility. However, there is no single study to investigate the redistributive characteristics of major public programs and the aggregate magnitude of expected financial wealth generated by the Turkish Social Security relative to other forms of household wealth. Studies that quantify the expected value of Social Security for different age cohort are limited. Has this expectation been declining for younger age cohorts in Turkey?

Following the Feldstein's seminal paper in 1974, the questions above have been addressed by many researchers for mostly developed countries by calculating the net present value of expected social security benefits and contributions for households. One common finding of these studies is that social security wealth is an important part of lifetime resources for households and its intergenerational distribution can affect economic dynamics. This paper is the first attempt within this literature to calculate the aggregate social security wealth (SSW) series for an emerging country, Turkey - that has the most generous social security system in the OECD region. One reason for this scarcity of studies might be the limited availability of data for developing countries. ${ }^{1}$ Even though Turkey is not immune to this sort of problem, it has relatively better data sources and a long history with a public social security system. Our simulations results that cover the period between 1970 and 2003 show that anticipated social security wealth is the biggest part of household wealth and therefore it should not be ignored in economic studies. In addition to the aggregate social security wealth series, we also analyze the redistributive characteristics of the system by calculating the expected implicit rate of return and the net gains and losses perceived by a new participant to the system in different age cohorts. Our principal finding is that Social Security in Turkey constitutes significant wealth transfers between different age cohorts.

The paper is organized as follows. Section 2 gives a brief literature review on the subject. The information about the Turkish social security system is provided in Section 3.

\footnotetext{
${ }^{1}$ Argentina is one of the few exceptions. To our knowledge, it is the only emerging country that has generational accounting calculations whose results are presented by Altamiranda (1999).
} 
Section 4 talks about the methods, assumptions, and data sources for our aggregate SSW series. The generational fairness of the system is discussed in Section 5. Our brief interpretation of the results is presented in Section 6.

\section{Literature Review}

Parametric reforms have been successful in postponing financial problems of PAYG systems at the cost of decreasing wealth for coming generations. With the current trends in demographics, parametric reforms have turned intergenerational wealth distributions into unsustainable Ponzi schemes. While the generational fairness of Social Security has been questioned by public, it has also produced a strong interest among researchers because of its potential effects on economic dynamics such as saving and consumption. The legacy debt cumulated by these parametric reforms has increased consumption for current generations and unpaid liabilities for unborn generations.

The effect of declining expectations in social security wealth on saving has become a major question. There are two major arguments in the literature that make the answer theoretically ambiguous: (1) if mandatory social security transfers between generations are offset by altruistic voluntary transfers, national saving may not be affected by social security transfers dictated by a PAYG system (Barro 1974, 1978, and 1989). (2) In a simple life-cycle model setting, social security contributions crowds-out personal retirement saving. However, this crowding-out is not necessarily hundred percent. Depending on the relative magnitudes of substitution and income effects, the introduction of PAYG system might even increase personal saving (Feldstein 1974). Therefore, understanding how a social security system can affect saving needs information on two grounds: (1) the significance of intergenerational wealth reallocations and (2) the magnitude of the crowding-out in personal saving by public pension wealth mandated by a PAYG system.

Empirical studies in evaluating the scale of these two measures have to quantify effects of Social Security on lifetime wealth. The importance of intergenerational wealth distributions on economic dynamics is formally conceptualized by the Generational Accounting approach (Auerbach, Gokhale, and Kotlikoff 1991). Unlike conventional public budgets, intertemporal government budgets calculate the present value of taxes and transfers that different age cohorts are expected to pay and receive over their remaining lives. In this sense, generational accounts include and hence explicitly calculate gains and losses resulted from Social Security for different age cohorts. The outcome of intertemporal budget calculations for twenty two countries including Argentina is published in a recent book (Auerbach, Kotlikoff, and Leibfritz 1999).

In addition to generational accounting calculations, several studies have attempted to quantify the significance of wealth redistributions among generations specifically caused by Social Security. Even though each of these studies represents a different methodology, in general they calculate the expected net present value of contributions and benefits based on survival probabilities for a representative individual in different age cohorts. There are two common ways to calculate social security wealth series: (1) at any given time, SSW series can be calculated for the rest of the lives of all different age cohorts and therefore only future taxes can be taken into the calculation and past taxes could be considered as "sunk"; (2) unlike the first method where SSW increases for older cohorts, it could also be calculated at any given time as a difference between the present value of incurred and expected lifetime contributions and benefits. While the first method is acceptable for aggregate SSW series for an economy, the second method is more appropriate for the purpose of finding lifetime wealth increments and losses of different age cohorts, genders, and income groups. The implicit internal rate of return 
(IRR) is a result of the second method and equates the present value of lifetime contributions to benefits that people in different circumstances anticipate. Since these simulations need a set of reliable data sources covering a relatively longer period of time, they have been done mostly for developed countries. One common finding of these studies is that the early cohorts received very high rates of return on their contributions, while later cohorts are likely to have sharply decreasing rates of return well below the rate of return available on private assets. Studies by Meyer and Wolff (1987) and Boskin et al. (1985) give comprehensive literature reviews on simulations of internal rate of return and wealth redistributions. Two books, Eugene (1994) and Feldstein and Liebman (2002), give more updated surveys on the same subject.

For the second question on whether or not pension wealth displaces personal saving, the studies need to quantify a social security variable in their regression analyses. Empirical studies on the subject are based on three different types of data set and therefore might be classified accordingly: time-series, cross-sectional, and cross-country analyses. ${ }^{2}$ The heart of these analyses is the calculation of the social security wealth variable. SSW, as a proxy for the future expected social security benefits and contributions, was conceptualized and calculated for the first time by Feldstein in his time-series study (1974). Because its complex simulation methods and many embedded assumptions, several researchers evaluate the results critically. The major criticism comes from Leimer and Lesnoy (1982). They argue that the expectation formation in the perception of benefit (and tax) factors is highly speculative ${ }^{3}$ and generate ten different methods for determining the expected benefit and tax ratios. In addition the these adjustments in the Feldstein simulations, they also generate their new ${ }^{4}$ calculations of social security wealth, and show that both algorithms fail to have a significant effect of social security on saving.

In his reply to these criticisms, Feldstein (1982) argues that SSW is only a proxy for people's perception of future social security wealth and it is not a precise variable but an approximation. Therefore an exact actuarial calculation may be further away from the appropriate variable than a less inclusive approximation. Any modification in that proxy would not necessarily conform to people's expectations.

Because of its complexity and sensitive assumptions, it has been also argued that empirical studies using aggregated or individual SSW series, which are not observable and have to be approximated, are of little importance. However, the same argument could be used against other approximations in many time-series and cross-section studies: human capital, discounted future labor income, and so on.

\footnotetext{
${ }^{2}$ Time-series analyses calculate the aggregate SSW series for the entire economy and then use it to see whether or not the aggregate consumption (or saving) over time is higher as the SSW gets higher. Unlike time-series analyses, cross section analyses estimate asset equations rather than consumption functions with individually calculated social security wealth proxies. Therefore, the majority investigates the substitution between pension and non-pension wealth and look at the behavior of a group of households prior to retirement. There are many important studies on time-series as well as cross-section analyses. See Esposito (1978), Magnussen (1994), CBO (1998), and Engen and Gale (1997) for the complete list.

${ }^{3}$ The ratio of first annuity to the last income is the benefit factor. The ratio of contributions to the current income is the tax factor.

${ }^{4}$ They improve Feldstein's SSW series in several points: First, they expand the time from 1972 to 1974; second, they use variable adjustment factors for labor force participation rates in each year. Besides, they use five different mortality tables for different periods. In addition to these improvements they also recalculate the dependent wife and surviving widow benefits by using more refined data.
} 


\section{Turkish Social Security System}

The old-age security in Turkey, initiated after the Second World War, consists of three state-managed pension schemes ${ }^{5}$ that pay an earning-related defined benefit financed on pay-asyou-go basis. In addition to its labor market distortions and redistribution to higher income groups, it is also financially insolvent. The lack of a minimum retirement age, which was removed in 1992, has been the major factor for the financial imbalance-Turkey had retirement ages as young as 47 years of age in SSK and 48 years of age in ES, the lowest in the world. ${ }^{6}$ Moreover, Turkey is the only country in the world that simultaneously had very low minimum contribution periods (in some cases as low as 10 years) and high replacement rates (90\% in SSK, $127 \%$ in Bag-Kur, and $106 \%$ in ES $)^{7}$ with a lack of minimum retirement age before the 1999 reform (The World Bank Country Economic Memorandum, 2000).

The weak link ${ }^{8}$ between contributions and benefits before 1999 created an incentive for workers to declare the earnings base for premium at a lower value. The high informal employment due to relatively high statutory contribution rates, the lack of automatic indexation of the contribution ceiling ${ }^{9}$ under high inflation conditions, and the low premium collection rates because of administrative inefficiencies worsened the already financially imbalanced system. As a result, the system became a major fiscal burden, damaging Turkey's macroeconomic stability. Coupled with other structural problems in the economy, the severe financial crisis early in 1999 forced Turkish government led by the World Bank to reform the impaired social security system in August 1999. This "parametric" reform was intended to achieve the actuarial balance of the PAYG system in the mid-term and to reduce pressure on the borrowing needs of the government.

Table 1: Pension and Income for Selected Countries in OECD (2002, in US dollars)

\begin{tabular}{lcccccc}
\hline & $\begin{array}{c}\text { Per Capita } \\
\text { GNI }\end{array}$ & $\begin{array}{c}\text { Average } \\
\text { Wage }\end{array}$ & $\begin{array}{c}\text { Replacement } \\
\text { Rate }\end{array}$ & $\begin{array}{c}\text { Gross } \\
\text { Pension } \\
\text { Wealth }\end{array}$ & $\begin{array}{c}\text { Relative } \\
\text { Pension } \\
\text { Wealth }\end{array}$ & $\begin{array}{c}\text { Relative } \\
\text { Pension } \\
\text { Level }\end{array}$ \\
Hungary & 5,100 & 4,187 & 75.4 & 55,000 & 11.7 & 72.2 \\
Slovak Republic & 4,080 & 3,031 & 48.6 & 27,000 & 7.9 & 47.9 \\
Czech Republic & 5,880 & 6,306 & 44.4 & 47,000 & 6.9 & 41.7 \\
Mexico & 5,950 & 6,180 & 36.0 & 28,000 & 4.5 & 35.7 \\
Poland & 4,680 & 6,456 & 56.9 & 51,000 & 7.7 & 55.5 \\
Turkey & $\mathbf{2 , 5 1 0}$ & $\mathbf{6 , 5 7 1}$ & $\mathbf{8 7 . 2}$ & $\mathbf{7 4 , 0 0 0}$ & $\mathbf{1 0 . 3}$ & $\mathbf{8 1 . 3}$ \\
United Kingdom & 25,560 & 29,133 & 37.1 & 172,000 & 5.5 & 37.1 \\
United States & 35,430 & 32,360 & 38.6 & 183,000 & 5.2 & 36.5 \\
Canada & 22,610 & 24,756 & 42.5 & 163,000 & 6.1 & 39.9 \\
OECD Average & & & $\mathbf{5 6 . 9}$ & $\mathbf{2 0 2 , 3 6 7}$ & $\mathbf{8 . 7}$ & $\mathbf{5 5 . 4}$
\end{tabular}

\footnotetext{
${ }^{5}$ Social Insurance Institution (Sosyal Sigortalar Kurumu - SSK) for wage earners in private and public sectors, BagKur (BK) for self-employed individuals and farmers, and Retirement Fund (Emekli Sandigi - ES) for civil servants

${ }^{6}$ The average minimum retirement ages for OECD countries are 64.4 for men and 63.9 for women in 2002 (OECD 2005).

${ }^{7}$ These rates reflects 2004 values and taken from "Proposal for Reform in the Social Security System" (2004).

${ }^{8}$ In SSK, pensions were linked to wages paid in the last five years and the same link was even worse in ES and BagKur: only the last year's wages were used to calculate pensions.

${ }^{9}$ The ceiling on wages subject to social security contribution in the fall of 1995 actually fell below the minimum wage. The World Bank Report (2000, 2003)
} 
The most fundamental characteristics of the Turkish social security system have been its generosity (relative to income) due to very young average retirement ages (in some cases 38 for women and 47 for $\operatorname{men}^{10}$ ), low minimum contribution periods, and high replacement rates. According to a new research by the OECD (2005), as seen in Table 1 above, a new entrant in Turkey has $\$ 74,000$ average gross pension wealth with $\$ 2,510$ per capita gross national income, while the same numbers are $\$ 183,000$ and $\$ 35,430$ for the US in 2002. In addition, Turkey's gross replacement rate $(87.2 \%)$ is the highest in the OECD region, which has $56.7 \%$ of the same rate as an average. ${ }^{11}$ While this generosity has paved the way for the collapse of the system's actuarial and financial soundness and still presents a big problem for the system's sustainability, one would expect that this generosity would also have strong effects on consumption and saving behaviors of individuals. It is this generosity that makes the Turkish case special relative to other developing countries in the literature.

\section{Aggregate Social Security Wealth Series for Turkey: Methods, Assumptions and Data Sources}

In calculating aggregate SSW series, we use simulations to convert assumptions about household's wages, survival rates, economy-wide growth rates of wages and annuities, interest rates, demographic projections, and possible future regulatory changes into expected present values of Social Security benefits and contributions for different genders, age groups, workers, retirees, and households with different marital status for the period between 1970 and 2003. The fundamental procedure in calculating SSW for a typical individual has the following two steps:

\section{Present Value of Future Benefits (SSWG):}

- If an individual at the age of $(a)$ in year $(t)$ survives to the retirement age $(r a)$, and if his current wage (or income that the old-age security is based on), $W_{(a, t)}$, grows at a constant rate of growth, $g$, then he will have an income at the retirement age of $\mathrm{ra}$ :

$$
W_{t+r a-a}=W_{t}(1+g)^{(r a-a)}
$$

- In order to calculate the first annuity for this individual, we use a benefit factor, $(b f)$, which is basically the ratio of his first annuity to his last wage (or to his insurable income if he is among self-employed individuals).

- Given the benefit factor, the individual will be entitled to his first annuity at $r a$, which is

$$
B_{(a, t)}=b f_{t} W_{t}(1+g)^{(r a-a)}
$$

- If we further assume that real annuities will grow after $r a$ by ga until the age of death $(d a)$, given the survival probabilities $\left(S_{(i, j)}\right)$ for that particular individual, the actuarial present value of future annuities $(P V A)$ can be calculated at $r a$, where $S_{(i, j)}$ presents the probability of living at least to the age of $j$, given that the person lived to the age $i$. With the personal discount rate $(d)$ for future real incomes, Equation (2) becomes at the age of $r a$ :

\footnotetext{
${ }^{10}$ See "Turk Emeklilik Sisteminde Reform" (The Reform in Turkish Pension System) TUSIAD November 2004 P.108

${ }^{11}$ Excluding Luxemburg which is an outlier with $101.9 \%$ gross replacement rate.
} 


$$
P V A_{r a}=\sum_{d a \geq n \geq r a} S_{(r a, n)} B_{(a, t)}(1+g)^{(n-r a)}(1+d)^{-(n-r a)}
$$

- At time ( $t$ ), after substituting $B_{(a, t)}$ (Equation 2) into Equation 3, the person has the following expected present value of benefits at the age of $a$ :

$$
\left.\left.S S W G_{(a, t)}=b f_{t} W_{t} S_{(a, r a)} \mid 1+g\right) /(1+d)_{-}^{T r a-a)} \sum_{d a \geq n \geq 65} S_{(r a, n)} \mid 1+g\right) /(1+d)_{-}^{\top n-r a)}
$$

This also includes survival probabilities between the age of retirement $(\mathrm{ra})$ and the current age $(a)$ at time $(t)$.

\section{Present Value of Future Contributions (SSTX):}

If the same individual at the age of $(a)$ in year $(t)$ survives to age $r a$, and if his current wage (or income that the old-age security is based on), $W_{(a, t)}$, grows at a constant rate of growth, $g$, then the expected present value of all his future contributions until age $r a$ can be calculated as follows:

$$
\left.\operatorname{SSTX}_{a, t}=\sum_{m=a}^{r a} S_{a, m} \theta_{t+m-a} W_{t} \mathbf{1}+g\right) /(1+d)_{-}^{\bar{m}-a},
$$

where $\theta$ is the ratio of social security taxes to his wages through his working years, and the person expects that at the age $m$ he will pay a tax of $T_{t+m-a}=\theta_{t+m-a} W_{t}(1+g)^{m-a}$. As noticed in Equation (5), SSTX treats contributions paid in the past as "sunk". This could be easily adjusted by adding the present value of all paid contributions to the equation.

Equations (4) and (5) are the fundamental equations in calculating the expected SSW, which is the difference between SSWG and SSTX. By construction, SSWG and SSTX equations above represent the present value of future benefits and contributions. However, for any individual or a representative household of a group, the same values can be found by taking the past contributions and benefits into the calculation. With necessary information about the parameters of the equations for a particular individual, SSWG and SSTX can be calculated explicitly for that individual (or household). Many cross-section studies on the subject have been calculating SSW values for individuals or households by using similar functions. Timeseries studies, on the other hand, use aggregated SSW series for economy-wise investigations. Before getting into the details of this aggregation method for the Turkish social security system, we should underline several common points that almost all simulations share in finding aggregate SSW series:

1. The calculations are mostly done in a partial-equilibrium setting in the sense that the effects of Social Security on economy-wise expected discount rates, wages, and growth rates during the lifespan of an individual or for the period covered in an economy are not followed.

2. Social Security benefits are usually limited to the retirement part of the programs. Benefits excludes other attached benefits (health care, etc.) provided by the system.

3. Studies assume that the entire tax burden shifts onto workers.

4. Calculations are not expected to be as precise as the exact actuarial values of SSW. They 
are only supposed to reflect magnitudes of individual or economy-wise perceived values that the presence of Social Security would offer. If the fundamental functions are consistent with the system, SSW simulations can provide important information about individual and aggregate differences among households and years to carry out an empirical research.

5. Since SSW is an expected value, a person does not have to be employed or a member of the system to have an expectation about the future social security entitlements. Besides, in a typical household, children and wives/husbands can have these expectations based on their legal ties to a person covered by Social Security, even if they are underage or not working as to be covered directly by the system.

6. Individuals form their expectations on the values of benefit and tax factors as well as discount and growth rates. Therefore, how these expectations can be formed is the most important assumption in simulations.

The aggregation of individual SSW values for different generations, age cohorts, and for the entire economy for any given period reveals generational fairness of the system and the share of SSW in total household wealth. The same fundamental equations are used for the aggregate SSW series with one major adjustment: because it is practically imposable to find individually recognized wages, per capita personal disposable income is used as "reference" income.

Aggregated SSW Series for Turkey: There are four major steps in constructing the aggregate SSW series for Turkey: The first step is to identify the "benefit and tax factors" with different assumptions in expectation formation. The second step is to create the demographics (including survival rates) of the labor market and current beneficiaries. The third step is to decide on the "reference income" for aggregation. The last step is to put all steps together in a software program to simulate a set of SSW series with different sets of assumptions. We calculated the SSW series for 34 years from 1970 to 2003 at 1987 prices. We chose this period because the data about the demographics of labor market were not readily available for earlier years.

1. Benefit and Tax Factors: The key components of the SSW simulations are the benefit and tax factors. The benefit factor is defined as the ratio of per retiree annual benefits to per capita reference income. Likewise, the tax factor is the ratio of social security taxes (contributions) per covered worker to per capita reference income. These ratios are not constant over the years and therefore how individuals perceive them for their future entitlements and liabilities becomes a critical assumption. Before discussing this assumption further, let us first explain how these factors are calculated for Turkey.

Benefit Factors (Ratios): The three public social security institutions, Social Security Institution (Sosyal Sigortalar Kurumu -- SSK) for wage earners, Bag-Kur (BK) for selfemployed people, and Pension Fund (Emekli Sandigi -- ES) for civil servants, provide a range of coverage. We use only old-age, disability and survivor (death) insurance (ODS) in our SSW simulations. First, we find the numerator of the ratio, per retiree (excluding survivors and disability retirees) annual old-age benefits, for each institution and each year. Even though we have a gender-based distribution of the numbers of retirees for each institution, some difficulties arise in obtaining the paid ODS benefits in terms of gender. Therefore, we make an educated assumption here to obtain the factor for males and females separately. We assume that per retiree old-age benefits for females are $30 \%$ less than the benefits for male retirees and calculate 
them as follows: ${ }^{12}$

$$
\begin{aligned}
& M n+F n=T n \\
& M b+F b=T b
\end{aligned}
$$

After dividing the second expression by $\boldsymbol{T n}$ and rearranging it, we get

$$
\frac{M b}{M n} \times \frac{M n}{T n}+\frac{F b}{F n} \times \frac{F n}{T n}=\frac{T b}{T n} .
$$

Since we assume that

$$
\frac{M b}{M n} x 0.7=\frac{F b}{F n},
$$

per retiree benefits are calculated for both genders as follows

$$
\frac{M b}{M n}=\frac{T b / T n}{M n / T n+0.7 x F n / T n} \text { and } \frac{F b}{F n}=\frac{T b / T n}{1 / 0.7 x M n / T n+F n / T n} .
$$

In the absence of personal disposable income series, we use per capita net private disposable income (NprvDI) for the denominator of the same ratio (benefit factor). NprvDI is also used as "reference income" in the entire simulation. Its derivation will be discussed in the third step and the table for each year's benefit factor is given at the end. As seen Figure 1 below, benefit factors over the years show a strong negative trend with very high $t$-values. Therefore, taking the benefit factor constant over the years is open to discussion.

Figure 1: Benefit Factors

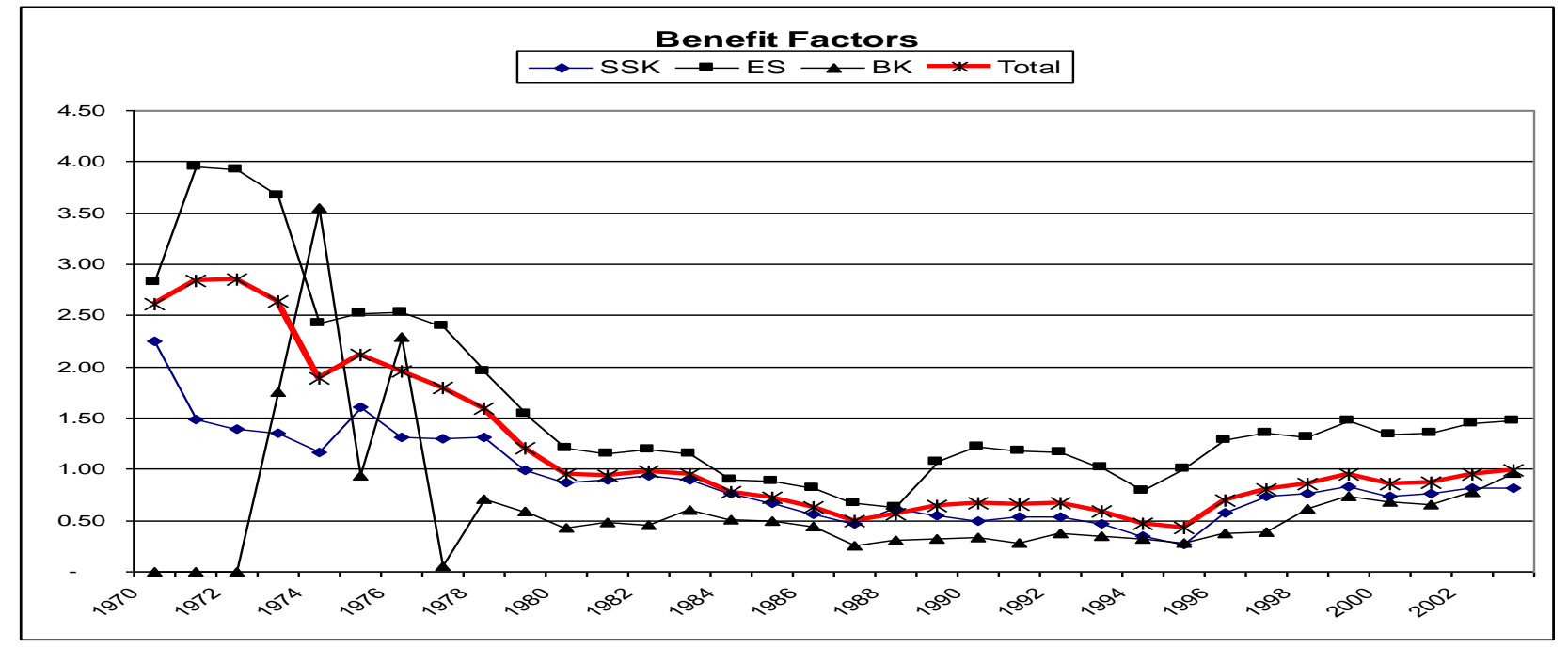

\footnotetext{
${ }^{12} \mathrm{M}, \mathrm{F}$, and T represent male, female, and total respectively. Subscripts $\mathrm{n}$ and b indicate 'numbers' and 'benefits' so that $\mathrm{Mn}$ and $\mathrm{Mb}$, for instance, represent the total number of male retirees and the total benefits paid to male retirees respectively.
} 
Tax Factors: In order to find the tax factor, which is the ratio of social security taxes (contributions) per covered worker to per capita "reference income", we first find the number of covered workers for each year, from 1970 to 2003, for each of the three social security institutions. As in the calculation of the benefit factor, we have the same difficulties in obtaining the incurred social security premiums in terms of gender. Therefore, we apply the same assumption here and reduce ODS contributions for females $30 \%$.

In calculating the incurred social security taxes, we find the premiums only for the ODS coverage. Since the total employer share is shifted onto workers through lower wages, the premiums are the sum of the employees' and employers' shares. Our findings about the tax ratios are given at the end. Even though it is not as strong as in benefits factors, tax factors also exhibit trends as seen below.

\section{Figure 2: Tax Factors}

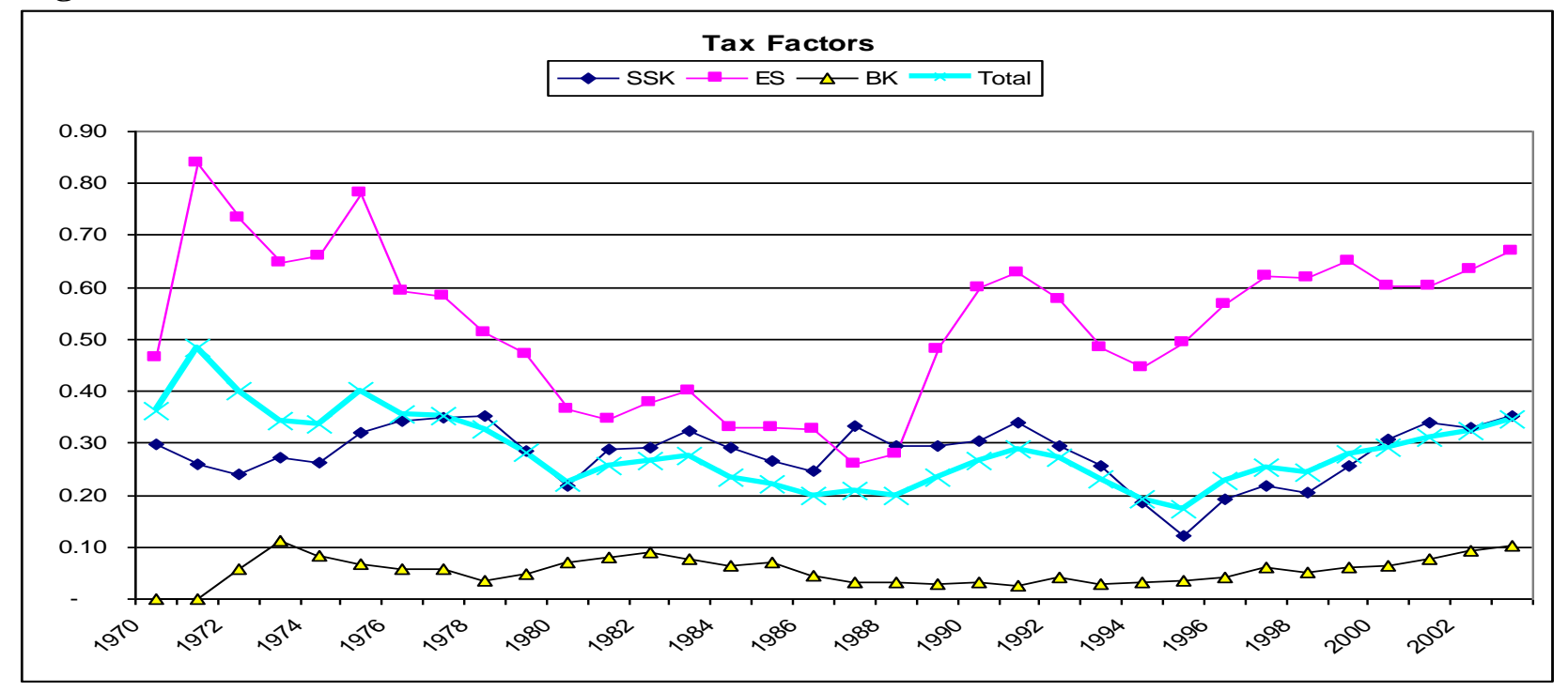

As stressed before, the assumption about how people perceive both benefit and tax factors is very critical in terms of finding SSW series that represent people's expectation. Because of strong trends in both factors, we think that SSW values simulated by average factors are not appropriate in representing people's expectations. However, in order to test the sensitivity of the SSW series to different assumption on expectations, we use three perception methods as explained below. ${ }^{13}$

Method 1: Individuals base their anticipated benefit and tax ratios on some average over the period of analysis ${ }^{14}$. Therefore the factors can be taken as constant as follows:

$$
\begin{aligned}
& \hat{b}_{t}=\bar{b} \\
& \hat{\theta}_{t}=\bar{\theta}
\end{aligned}
$$

$b$ denotes the benefit factor and $\theta$ denotes the tax factor and the values for three institutions are given below.

\footnotetext{
${ }^{13}$ We suggest that these methods should be extended and changed depending on the nature of investigation.

14 The factor with a bar represents the average, and with a hat, expectation of the factor.
} 


\begin{tabular}{lccccccccc} 
& SSK & \multicolumn{2}{c}{ ES } & \multicolumn{3}{c}{ BK } & \multicolumn{3}{c}{ Total } \\
& Male & Female & Male & Female & Male & Female & Male & Female & Total \\
\hline Benefit Factors & 0.93 & 0.65 & 1.76 & 1.23 & 0.71 & 0.50 & 1.24 & 0.87 & 1.17 \\
Tax Factors & 0.29 & 0.20 & 0.58 & 0.41 & 0.06 & 0.04 & 0.30 & 0.21 & 0.28
\end{tabular}

Method 2: Individuals expect the future benefit and tax factors to equal their current benefit and tax factors. That is:

$$
\begin{aligned}
& \hat{b}_{t}=b_{t} \\
& \hat{\theta}_{t}=\theta_{t}
\end{aligned}
$$

Method 3: Individuals are able to consider both past and current values of the benefit and tax factors. They form their expectation by an adaptive expectation process.

$$
\begin{aligned}
& \hat{b}_{t}=\delta \hat{b}_{t-1}+(1-\delta) b_{t} \\
& \hat{\theta}_{t}=\beta \hat{\theta}_{t-1}+(1-\beta) \theta_{t}
\end{aligned}
$$

In this method, we apply a 3-year moving average with the weights $(\beta, \delta)$ of $50 \%$ for the current year and $25 \%$ for the last two years each. These weights are chosen arbitrarily. The list of values for the last two methods is given in appendices.

2. Demographics and Survival Rates: Because of the limited availability of the necessary data, the most difficult part of constructing the SSW series for Turkey is the part that deals with the demographics of the labor force and the current beneficiaries. We used several different sources for our data collection and had to estimate some years. There are six main groups in calculating the SSW series: workers, workers' wives, old-age retirees, old-age retirees' wives, disability retirees, and survivors

Workers: Since the ultimate task is to construct expected social security wealth, the ultimate number of people who may perceive this wealth at working-age, is not simply the number of individuals who actively contribute to one of the public social security plans in any given year, rather the number of all individuals who can expect to receive SSW from a public social security system in the future. ${ }^{15}$ In other words, even if a person at working-age is not currently in the labor force, she may expect to have some future retirement benefits conditional on future employment opportunities. ${ }^{16}$ Therefore, SSW simulations should contain current and prospective workers together.

In aggregation of SSW series, the major question becomes how many people at any given age could expect to have old-age benefits regardless of whether or not they are in the labor force. We estimate the ultimate number of persons for each age group who would eventually be entitled to a social security benefit by the number of current workers adjusted for labor force participation. We use the maximum labor force participation rate (MaxLFPR) in each year for

\footnotetext{
${ }^{15}$ This is the main difference between the calculation of SSW series in the literature and the "Pension Wealth" calculated by OECD for 2002 (Pension at a Glance 2005, OECD).

${ }^{16}$ For example, a student in the age group of 15-19 can expect to have retirement benefits at 55, even if she is not currently in the labor force. Likewise, an older person, who is at the age of 57 and not currently in the labor force, might have been employed before and therefore she may expect to have retirement benefits even she is not currently in the labor force.
} 
each age group to find the number of individuals who may have expected SSW. In other words, we applied the following method for every age group and year:

Total Number of Individuals with SSW = Civilian Population (year, age, gender) X MaxLFPR (year, gender) X Employment Rate (year, age, gender)

We constructed the demographics of the Turkish labor force market from 1970 to 2003. We have the following table (Table 2) for every year in that period.

Table 2: An Example from the Labor Demographics

\begin{tabular}{|c|c|c|c|c|c|c|c|c|c|c|c|c|c|}
\hline \multirow[b]{2}{*}{1970} & & \multicolumn{10}{|c|}{ Age Groups } & \multicolumn{2}{|c|}{ (Thousands) } \\
\hline & & $15-19$ & $20-24$ & $25-29$ & $30-34$ & $35-39$ & $40-44$ & $45-49$ & $50-54$ & $55-59$ & $60-64$ & $65+$ & Total \\
\hline \multirow[t]{7}{*}{ Male } & Population & 1,849 & 1,467 & 1,148 & 978 & 1,097 & 903 & 692 & 473 & 588 & 454 & 724 & 10,371 \\
\hline & Labor Force & 1,210 & 1,244 & 1,045 & 903 & 1,025 & 845 & 628 & 428 & 504 & 367 & 498 & 8,697 \\
\hline & Employment & 1,134 & 1,166 & 979 & 846 & 961 & 792 & 589 & 401 & 472 & 344 & 467 & 8,152 \\
\hline & $L F P R$ & $65 \%$ & $85 \%$ & $91 \%$ & $92 \%$ & $93 \%$ & $94 \%$ & $91 \%$ & $90 \%$ & $86 \%$ & $81 \%$ & $69 \%$ & $84 \%$ \\
\hline & Highest LFPR & $94 \%$ & $94 \%$ & $94 \%$ & $94 \%$ & $94 \%$ & $94 \%$ & $94 \%$ & $94 \%$ & $94 \%$ & $94 \%$ & $94 \%$ & \\
\hline & $\underline{P}$ & $70 \%$ & $91 \%$ & $97 \%$ & $99 \%$ & $100 \%$ & $100 \%$ & $97 \%$ & $97 \%$ & $92 \%$ & $86 \%$ & $74 \%$ & \\
\hline & $\underline{W / P}$ & 1,621 & 1,286 & 1,007 & 857 & 962 & 792 & 607 & 415 & 515 & 398 & 635 & 9,095 \\
\hline \multirow[t]{7}{*}{ Female } & Population & 1,876 & 1,308 & 1,062 & 1,034 & 1,044 & 841 & 668 & 476 & 545 & 439 & 802 & 10,096 \\
\hline & Labor Force & 1,036 & 705 & 548 & 536 & 538 & 455 & 360 & 258 & 271 & 212 & 288 & 5,209 \\
\hline & Employment & 971 & 661 & 514 & 503 & 504 & 426 & 338 & 242 & 254 & 199 & 270 & 4,882 \\
\hline & LFPR & $55 \%$ & $54 \%$ & $52 \%$ & $52 \%$ & $52 \%$ & $54 \%$ & $54 \%$ & $54 \%$ & $50 \%$ & $48 \%$ & $36 \%$ & $52 \%$ \\
\hline & Highest LFPR & $55 \%$ & $55 \%$ & $55 \%$ & $55 \%$ & $55 \%$ & $55 \%$ & $55 \%$ & $55 \%$ & $55 \%$ & $55 \%$ & $55 \%$ & \\
\hline & $\underline{P}$ & $100 \%$ & $98 \%$ & $94 \%$ & $94 \%$ & $93 \%$ & $98 \%$ & $98 \%$ & $98 \%$ & $90 \%$ & $88 \%$ & $65 \%$ & \\
\hline & $W / P$ & 971 & 677 & 550 & 535 & 540 & 435 & 346 & 246 & 282 & 227 & 415 & 5,225 \\
\hline
\end{tabular}

The derivation of $W / P$ in Table 2 is given below:

$$
\begin{aligned}
& P_{y, a}=\frac{\operatorname{LFPR}_{y, a}}{\operatorname{MaxLFPR}_{y}} \\
& \frac{W_{y, a}}{P_{y, a}}=W_{y, a} *\left(\frac{1}{\operatorname{LFPR}_{y, a}}\right) * \operatorname{MaxLFPR}_{y} \\
& W_{y, a}=\left(1-{\text { Unemployment } \%_{y, a}}\right) * L F_{y, a} \\
& \frac{W_{y, a}}{P_{y, a}}=\left(1-{\text { Unemployment } \%_{y, a}}\right) * L F_{y, a} *\left(\frac{1}{L F P R_{y, a}}\right) * \operatorname{MaxLFPR}_{y} \\
& \Rightarrow\left(1-\text { Unemployment }_{y, a}\right) * \mathrm{POP}_{y, a} * \text { MaxLFPR }_{y}
\end{aligned}
$$

where $W$ is the number of employed people, $L F$ is Labor Force and $P O P$ is Population.

Subscripts, $a$ and $y$, denote age groups and years respectively. Consistent with the methodology described above, the last expression is the number of people that would be employed if the maximum (prime age) labor force participation rate (MaxLFPR) were applied for this age group. This could be interpreted as the number of people in this age group who would expect to receive 
benefits when they retire. ${ }^{17}$

Because the State Institute of Statistics' (SIS) Labor Force Database starts from 1988, we could use them only for the years between 1988 and 2003 to build the tables. Before 1988, we utilized Bulutay's (1995) study for finding the numbers of employment, labor force and civilian population. Because Bulutay's (1995) study is not based on gender and age, we, therefore, referred to the International Labor Organization's (ILO) database for 1970, 1975, 1980 and 1985 in order to estimate gender and age distributions for these measures.

Unfortunately this is not the end of the story for finding the number of individuals who may have a perception of social security wealth. The ratio of number of individuals who are actively contributing to a public social security program to the total employment is very low in Turkey. ${ }^{18}$ Even though this ratio has been improving since 1970, as shown in the following Table 3, more than $40 \%$ of the employed population is not contributing to the public pension system even in the year 2003.

\section{Table 3: Covered Employment Based on Gender ${ }^{19}$}

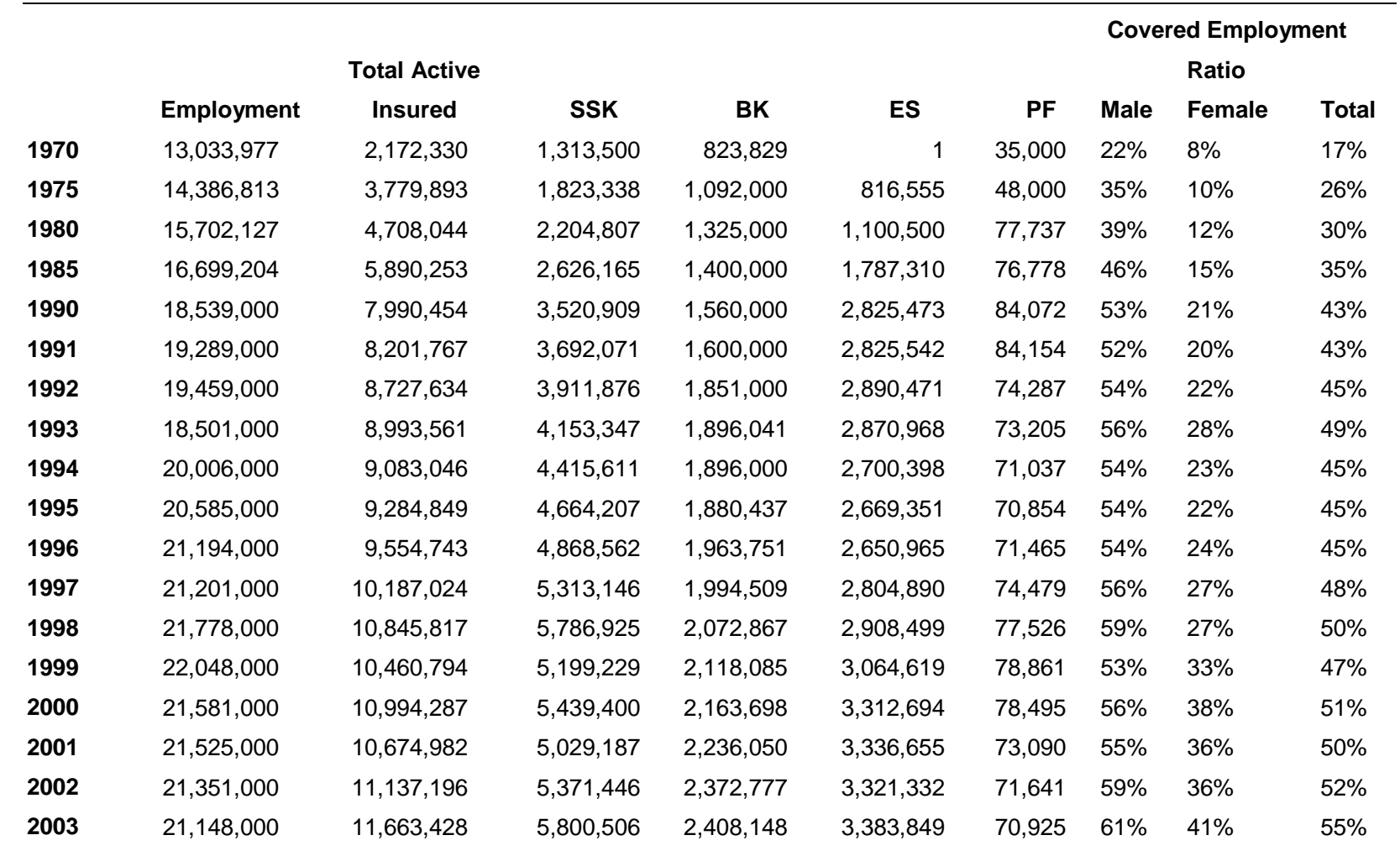

Sources: The data is collected from SIS and Devlet Planlama Teskilati (State Planning Organization - SPO).

If we discount the number of individuals $(W / P)$ by these ratios, we implicitly assume that people who do not contribute to one of the social security programs any given year expect that

\footnotetext{
${ }^{17}$ The adjustment factor, $\mathrm{P}$, is constant in Feldstein's (1974) calculation for the entire period. We calculate it for each year.

${ }^{18}$ The number of active insured persons also includes voluntary active insured individuals, farmers who are contributing to the public social security system and workers who are covered by private funds.

${ }^{19}$ Social Security Institution (Sosyal Sigortalar Kurumu -- SSK) for wage earners, Bag-Kur (BK) for self-employed people, and the Pension Fund (Emekli Sandigi -- ES) for civil servants and private funds (PF) for people who work in a company with private retirement fund.
} 
they will never contribute to the system later. However, as seen in Figure 2 above, the total ratio for covered workers has improved from $17 \%$ to $55 \%$ in 33 years and is expected to continue improving in the future with the help of several administrative reforms achieved after 1999. That is, if we discount the numbers in 1970 by $83 \%$, for example, we should assume that only $17 \%$ of the people in an age group (say 15-19) could expect to have a social security wealth in the future. However, in five years, the ratio improves $60 \%$ from $17 \%$ to $26 \%$. The question then becomes whether or not the additional 9\% people covered in 1975 can foresee this improvement and expect some future social security wealth in 1970 ?

In order to avoid a speculative assumption about people's perception of this improvement, we assume that people are not able to anticipate that the public social security coverage will improve for the coming years. This assumption is also consistent with the second perception method, which, we believe, is the best method for Turkey. Barro (1978) criticized Feldstein's SSW series, which uses the current coverage rates and the average benefit factor, by indicating that "the treatment of coverage and benefit rates (factors) is also asymmetric in that anticipated future coverage is assumed to correspond to current coverage, (...), while anticipated benefit rates are invariant - hence SSW - with respect to changes in actual benefit rates" (p.15). In order to include those uncovered employees, however, this assumption can be changed by forming a "reasonable" expectation method for the perception of future improvements. Our simulation program is adjustable in terms of this assumption.

Workers' Wives: After having the final gender and age specific base numbers for potential workers for each year, we also estimated the number of dependents who may expect to have social security wealth in the future conditional on the potential workers' expected retirement benefits. In other words, if a worker is married, his wife can have an expectation about future social security wealth conditional on her husband's future retirement benefits. For this, we made the following assumptions:

- Only wives have SSW expectations. We assume that workers' children, as dependents, don't have SSW expectations.

- If the worker dies, the benefit passes to his dependents with a generalized discount rate for all three social security systems, which is $75 \%{ }^{20}$.

- Wives are 3 years younger than workers.

- We used "Single Ratio" (from SIS's related statistics) for workers to estimate the number of married male workers for each age group and discounted the number of wives by these ratios.

Current Old-Age Retirees: In order to find the number of beneficiaries who receive annuities from the public social security system, we used the data privately provided by SSK, $\mathrm{BK}$ and ES. As explained before, the number of retirees includes all individuals who receive only old-age benefits from the public social security system. We used gender base per retiree benefits and numbers to calculate SSW series for each public pension scheme. Since we could not have detailed age distribution, we used average ages for each scheme and gender.

\footnotetext{
${ }^{20}$ There are several important rules in calculating survivor's annuities. These rules are slightly different among the three programs. The major rules are as follows: a wife's employment status does not affect her eligibility for survival benefits. A worker in SSK must pay 1800-day premium out of 7000 days in order for his dependents to be eligible for retirement benefits. If the worker dies in a work accident, this rule does not apply and dependents receive full retirement benefits. If wives do not have kids who are eligible to survivor's benefits, wives receive $75 \%$ of benefits, otherwise the ratio becomes $50 \%$ and the rest is distributed to eligible children and parents (of worker). For BK and ES, a 5-year and 10-year paid premium periods (respectively) are sufficient for a worker's dependents to have retirement benefits. The other rules for ES and BK are similar to those for SSK.
} 
Retirees' Wives: Similar to expectations of workers' wives, we estimate the number of wives who may expect to have some social security wealth, conditional on the retirees' expected retirement benefits. We use the same assumptions as used in estimating workers' wives expectations.

Disability Retirees: We find the number of individuals who are retired under the disability coverage for each public pension scheme and use an average age for each gender and scheme. We have detailed information about the number of retirees based on gender for SSK. However, we had to estimate this gender distribution for ES and partly for BK. We assumed that $80 \%$ of disability retirees are male for ES and it is $93 \%$ for BK. Since the number of total disability retirees is about as low as 36,000 in 2003 for ES and BK, a possible mistake in the gender distribution is negligible in the overall SSW simulations.

Survivors: We have three types of survivors: wives, orphans and workers' spouses. We find the numbers of each who receives survival benefits from SSK, ES and BK. We ignore the gender distribution since the majority of the survivors are female (wives, daughters and mothers). We use average ages for wives, orphans and spouses for each scheme and each year. In addition, we make the following assumptions:

- We assume that orphans could receive survivor benefits for ten years.

- Since the number of spouses is very low, we consider spouses and wives as one group.

- Because we do not have exact numbers of wives and orphans for ES separately, we assume that wives and veterans make up $55 \%$ of the all survivors in ES and the rest is orphans

Survival Probabilities: Turkey does not have its own mortality rate tables. Therefore, the private pension schemes in Turkey have been using the mortality rates calculated for the U.S. There are four types of mortality rates commonly used in Turkey: CSO 1980, CSO 53-58, ADST 49-51, and Heubeck Fischer tables for disabled persons. ${ }^{21}$ These mortality tables are also allowed by the government agencies regulating the private pension market in Turkey. We have chosen ADST 49-51 for the following reason: it is the oldest mortality table among the three and therefore the rates are higher than the others. Even though we believe that the differences among these three tables would not have significant effects on the SSW series, by selecting the "worst" mortality rates, a kind of adjustment in terms of mortality rates was made for the difference between Turkey and the U.S.

Table 4: Portion of Survival Probabilities for Males in Turkey

\begin{tabular}{|c|c|c|c|c|c|c|c|}
\hline \multirow[b]{2}{*}{$X$} & \multirow{2}{*}{$\begin{array}{c}\text { Female } \\
q x\end{array}$} & \multirow{2}{*}{$\begin{array}{c}\text { Male } \\
q x\end{array}$} & \multicolumn{2}{|c|}{$\begin{array}{l}\text { Person Alive } \\
\text { at the age of } X\end{array}$} & \multicolumn{2}{|c|}{ Life Tables Death } & \multirow{2}{*}{$\begin{array}{c}\text { Prob. Of } \\
\text { Survival } \\
\text { up to age } X \\
\text { MALE }\end{array}$} \\
\hline & & & FEMALE & MALE & FEMALE & MALE & \\
\hline $\mathbf{0}$ & 0.04909 & 0.06177 & $10,000,000$ & $10,000,000$ & 490,900 & 617,700 & 1.00000 \\
\hline 1 & 0.00360 & 0.00416 & $9,509,100$ & $9,382,300$ & 34,233 & 39,030 & 0.93823 \\
\hline 2 & 0.00215 & 0.00246 & $9,474,867$ & $9,343,270$ & 20,371 & 22,984 & 0.93433 \\
\hline 3 & 0.00164 & 0.00194 & $9,454,496$ & $9,320,285$ & 15,505 & 18,081 & 0.93203 \\
\hline 4 & 0.00127 & 0.00153 & $9,438,991$ & $9,302,204$ & 11,988 & 14,232 & 0.93022 \\
\hline 5 & 0.00099 & 0.00121 & $9,427,003$ & $9,287,971$ & 9,333 & 11,238 & 0.92880 \\
\hline 6 & 0.00082 & 0.00102 & $9,417,671$ & $9,276,733$ & 7,722 & 9,462 & 0.92767 \\
\hline 7 & 0.00063 & 0.00094 & $9,409,948$ & $9,267,271$ & 5,928 & 8,711 & 0.92673 \\
\hline
\end{tabular}

${ }^{21}$ We thank to Aviva Life Insurance for providing these mortality tables. 
In order to show how the survival probabilities are calculated, a small part of the table for males is given in Figure 4 above. ${ }^{22}$ In this table, the ADST 49-50 columns show the mortality rates. We start with 10 million individuals at age zero. For each of the following age, we found the number of deaths and the probability of survival up to any given age. We calculated the conditional probabilities in order to find the probability of survival up to a specific age given that the person lived up to a given age for each gender.

3. Reference Income: We need a "reference income" to calculate SSW series in two places: (1) in the calculation of benefit and tax factors, explained in the first step; (2) in the calculation of the first annuities, which will be explained in the last step. The SSW series are calculated in the literature by using personal disposable incomes (PDI). Unfortunately, PDI series based on surveys do not exist for Turkey.

As mentioned in the first step, we use Net Private Disposable Income (NPrvDI) in constructing SSW series. We fist attempted to create a "generated" PDI by using national account identities as follows:

$$
P D I \approx N N P-T X+T R-R E+N I N T^{23}
$$

However, because of the difficulties in finding reliable information in Turkey about the components of PDI above, we decided to use Net Private Disposable Income. The difference between NprvDI and PDI is simply RE shown below by using a textbook version of national account identity:

$$
\begin{aligned}
& G N P=C+I+G+N X+N e t \text { Factor Incomes from Abroad }(N F I) \\
& G N P-T X+T R+N I N T=C+I-(T X-G-T R-N I N T)+(N X+N F I)
\end{aligned}
$$

After adding $T X$ (taxes), TR (transfers), and NINT (net interest rates paid by government) both sides, the left hand side of the second identity above is Gross Private Disposable Income $(G P r v D I)$ and the first and second parentheses in the right side are government saving $(G S)$ and foreign sources $(F S)$ respectively as expressed below:

$$
G P r v D I=C+I-G S+F S^{24}
$$

Since $G P r v D I=G N P-T X+T R+N I N T$, if the consumption of capital $(C o C)$ subtracted from both sides, we get

\footnotetext{
${ }^{22}$ In the table, $q x$ denotes the mortality rate for the age $x$.

${ }^{23}$ Net National Product $(N N P)=G N P-$ Depreciation

Net Income $(N I)=N N P-$ Indirect Taxes $(\operatorname{InTX})+$ Subsidies

$P D I=N I-($ Corporate Profits-Corporate Dividends $)+$ Net Interest $(N I N T)+($ Transfers $(T R)$-Contribution to Social Security $(S S))$ - Personal Taxes (PrsTX)

Since $($ Corporate Profits-Corporate Dividends $)=($ Corporate Taxes $($ CorpTX $)-$ Retained Earnings $(R E))$

$P D I=N I-(\operatorname{CorpTX}+R E)+N I N T+T R-S S T X-P r s T X$

$P D I=N N P-($ IndTX + Subsidies $)-($ CorpTX $+R E)+N I N T+T R-S S T X-$ PrsTX

If we group taxes then

$P D I=N N P-(I n d T X+C o r p T X+S S T X+P r s T X)+T R+N I N T-R E$

Since the first parenthesis on the right hand side is simply TX (Taxes) we can generate the following identity for national account:

$P D I \approx N N P-T X+T R-R E+N I N T$. A similar method is used by Meguire (1998).

${ }^{24}$ GprvDI is also calculated by SPO since 1975 in "General Macro Balance of the Economy" using similar methods.
} 


$$
N P r v D I=N N P-T X+T R+N I N T
$$

As seen from this identity, the difference between NprvDI and PDI is simply RE about which we do not have any information. However, as long as individuals perceive undistributed profits as capital gains (hence a part of their income), the difference between NprvDI and PDI is expected to be insignificant. ${ }^{25}$ We used the following NprvDI definition as our reference income series in our calculations.

$$
N p r v D I=C+I-G S+F S-C o C
$$

4. Putting All Pieces Together: In order to have the SSW series, the SSWG and SSTX series should be constructed first. We summarize the calculations in Figure 4 and the major assumptions are given below.

(1) The critical assumptions are the personal discount rate $(d)$, and the real income growth rate $(g)$. For the growth rate, we looked at the entire period and found approximately $1.9 \%$ average growth for per capita GDP and NPrvDI. Therefore, the growth rate for the real income is taken as $2 \%$ in our entire SSW series. For the personal discount rate $(d)$, we calculate the real interest rates for each year by consumer price inflation and time-deposit interest rates. ${ }^{26}$ In our calculation, the average real interest rate is found to be about zero. One reason for this near-zero real interest rate is that the nominal rates were not free before 1980 and, therefore, the real interest rates were mostly negative up to 1980. After the financial liberalization during the early $1980 \mathrm{~s}$, the average real interest rate started to rise to $1.6 \%$ for the period between 1980 and 2003. W made it adjustable and initially took it to be $3 \%$ for our SSW calculations.

Table 5: Average Ages $^{27}$

\begin{tabular}{lllllll}
\hline & \multicolumn{2}{c}{ SSK } & \multicolumn{2}{c}{ ES } & \multicolumn{2}{c}{ BK } \\
& $\mathbf{M}$ & $\mathbf{F}$ & $\mathbf{M}$ & $\mathbf{F}$ & $\mathbf{M}$ & $\mathbf{F}$ \\
\cline { 2 - 7 } Retirement age & 55 & 55 & 55 & 55 & 55 & 55 \\
Maximum age & 85 & 85 & 85 & 85 & 85 & 85 \\
Average Age for Retirees & 59 & 59 & 60 & 55 & 65 & 63 \\
Average Age for Disability Retirees & 60 & 57 & 60 & 55 & 61 & 63 \\
& $\mathbf{W \& S}$ & $\mathbf{O}$ & W\&S & $\mathbf{O}$ & W\&S & $\mathbf{0}$ \\
Average Age for Survivors & 62 & 29 & 65 & 34 & 62 & 29
\end{tabular}

(2) The other key parameter is the average retirement age. We used the related information from the three public social security programs and found that 55 could be taken as the average age for retirement for the entire public social security system. Therefore, we used 55 for both genders and each year as the average retirement age in both the $S S W G$ and SSTX calculations for working-age individuals. ${ }^{28}$ Because of the social security reform initiated in 1999, we use 58 (female workers) and 60 (male workers) for 15-19 and 20-24 age groups respectively after 1999.

\footnotetext{
${ }^{25}$ See Ando and Modigliani (1963).

${ }^{26}$ Real Interest Rate $=($ Nominal Interest Rate - Inflation $) /(1+$ Inflation $)$.

${ }^{27} \mathrm{M}$, male; F, female; W\&S, wives and spouses; O, orphans. In ES, W\&S includes veterans.

${ }^{28}$ After the reforms since 1999, the retirement age has been increased to 58 (female) and 60 (male) for new entrants. These ages were reduced to 56 and 58 respectively in 2002. These minimum ages are phased-in gradually for the previously insured employees.
} 
We also take 85 as the maximum age in all calculations. ${ }^{29}$ The average ages that we use in our calculations are summarized in Table 5 above.

(3) As Figure 3 below shows, there are fluctuations around the average rate of $0.5 \%$ in the growth of per retiree annuities (ODS) in real terms. Even though the same average for the last 24 years (1980-2003) is $2.4 \%$, we calculated SSW series with and without $2 \%$. In other words, we assumed that annuities grow only by the price inflation with the zero-percent real growth rate. ${ }^{30}$

Figure 3: Growth in Annuities (with 1987 Prices)

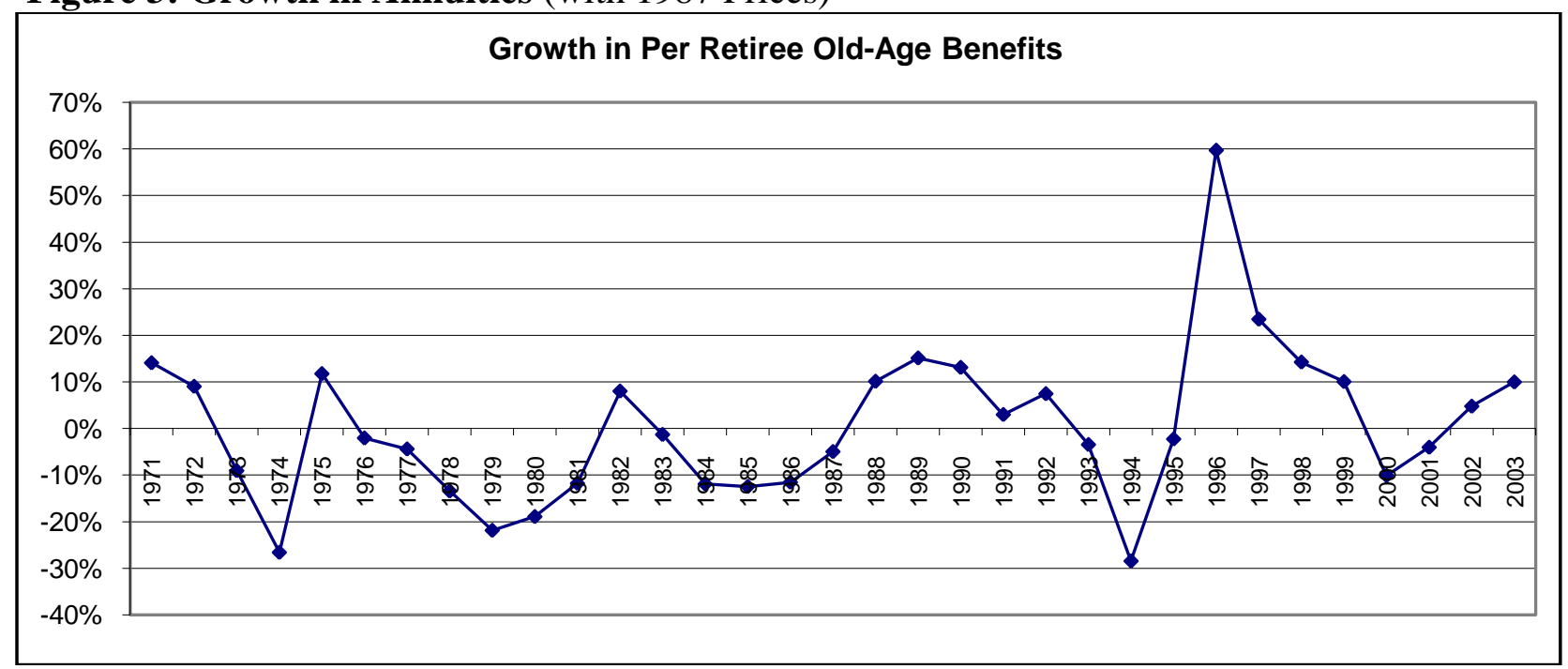

(4) Since we were not able to obtain a gender base benefit and tax information, we assumed that the per capita old-age benefits and ODS taxes would be $30 \%$ less for females than for males. ${ }^{31}$ Therefore, instead of dealing with insufficient data and sensitive assumptions to calculate the "precise" values, we used a generalized discount factor to reflect the gender difference in SSW calculations. ${ }^{32}$ We believe that a 30 -percent discount for both factors is a reasonable and modest estimation for Turkey. This discount rate can be changed to test the sensitivity of the results to this discrimination.

(5) Similarly, since we did not have details about the benefit distribution between orphans and wives, we reduced per beneficiary benefits $50 \%$ for orphans using the same method as in benefit and tax factors calculations.

(6) $P$, the labor force adjustment factor is the same for all years in Feldstein's SSW calculations, which is criticized by Leimer and Lesnoy (1980). We use the labor force adjustment factor, $P$, which varies each year. Unlike Feldstein's method (1974), we adjusted the number of workers by MaxLFPR in SSTX calculations.

(7) Since we do not have the number of covered people based on gender up to 1993 for ES, we use the same percentage for the gender distributions between 1970 and 1992 as in 1993.

(8) We use the total "statutory revenues" as premiums received by ES. Since ES provides only ODS coverage we believe that any possible difference would be negligible.

\footnotetext{
${ }^{29}$ Maximum life expectancies are projected 80 for males and 83 for females at age 65 for 2040 by OECD (2005).

${ }^{30}$ However, if we remove the outlier growth $(60 \%)$ in 1996 , the average approaches to zero.

${ }^{31}$ For example, the male benefit and tax factors are twice higher than the female factors in the U.S. (Feldstein 1974).

${ }^{32}$ For this assumption, we made use of SIS's Social Structure and Gender Statistics in Income Distribution Study (1994).
} 
(9) Since BK started providing health coverage after 1985, we discounted total premiums collected $50 \%$ for ODS coverage.

(10) In ES survivors group, we put wives, spouses and veterans together under the number of wives.

(11) Individuals, once they are covered by the system, have full career paths without any interruptions. In addition, as the time goes by, survival probabilities should change. We ignore these changes in survival probabilities and used only one series of survival probabilities in simulations.

\section{Figure 4: Aggregate SSWG and SSTX Definitions}

$\underline{S W W G}$

Workers $\left.\left.\quad S S W G_{t}=\sum_{a=15}^{r a}\left(W_{a, t} / P_{a, t}\right)^{G} C_{t}^{G} b f_{t}^{G} Y_{t} S_{(a, r a)}^{G} \mid 1+g\right) /(1+d)_{-}^{\operatorname{Tra} a-a)} \sum_{n=r a}^{85} S_{(r a, n)}^{G} \mathbf{1}+g a\right) /(1+d)_{-}^{-(n-r a)}$

Workers'Wives

$\left.S S W G_{t}=\sum_{a=15}^{r a}\left(W_{a, t} / P_{a, t}\right)^{M} C_{t}^{M} b f_{t}^{M} S r^{M} Y_{t}(B R)\left(S_{(a-3, r a)}^{F}\right)\left(1-S_{(a, r a)}^{M}\right) \mid 1+g\right) /(1+d)_{-}^{\text {Tra-a })}$

$\left.\sum_{n=r a}^{85} S_{(r a, n-3)}^{F} 1+g a\right) /(1+d){ }_{-}^{\text {Tra-n) }}$ plus

$\left.\left.\sum_{a=15}^{r a}\left(W_{a, t} / P_{a, t}\right)^{M} C_{t}^{M} b f_{t}^{M} s^{M} Y_{t}(B R)\left(S_{(a-3, r a)}^{F}\right)\left(S_{(a, r a)}^{M}\right) \boldsymbol{|} 1+g\right) /(1+d)_{-}^{T r a-a)} \sum_{n=r a}^{85}\left(S_{(r a, n-3)}^{F}\right)\left(1-S_{(r a, n)}^{M}\right) \boldsymbol{|} 1+g a\right) /(1+d)_{-}^{\top n-r a)}$

Retirees

$$
\left.S S W G_{t}=N_{t}^{G} A V B_{t}^{G} \sum_{n=\text { ara }}^{85} S_{(\text {ara }, n)}^{G} \mathbf{1}+g a\right) /(1+d)_{-}^{\Upsilon(n-a r a)}
$$

Retirees' Wives $\left.\quad S S W G_{t}=N_{t}^{M}\left(s r^{M}\right)(B R) A V B_{t}^{M} \sum_{n=a r a}^{85}\left(S_{(a r a, n-3)}^{F}\right)\left(1-S_{(a r a, n)}^{M}\right) \mid 1+g a\right) /(1+d)_{-}^{(n-a r a)}$

Disability Retirees

$$
\left.S S W G_{t}=N D_{t}^{G}\left(A B D_{t}\right) \sum_{n=a r a}^{85} S_{(a r a, n)}^{G} \backslash 1+g a\right) /(1+d)_{-}^{T n-a r a)}
$$

Survivors -- Wives

$$
\left.S S W G_{t}=N S_{t}^{w}\left(A B S W_{t}\right) \sum_{n=a r a}^{85} S_{(\text {ara }, n)}^{F} \mid 1+g a\right) /(1+d)_{-}^{T n-a r a)}
$$

Survivors - Orphans

$$
\left.S S W G_{t}=N S_{t}^{O}\left(A B S O_{t}\right) \sum_{n=\text { ara }}^{a r a+10} S_{(a r a, n)}^{F} \mathbf{1}+g a\right) /(1+d)_{-}^{(n-a r a)}
$$

$\underline{S S T X}$

Workers $\left.\quad \operatorname{SSTX}_{t}=\sum_{a=15}^{r a}\left(W_{a, t} / P_{a, t}\right)^{G} C_{t}^{G} \theta_{t}^{G} Y_{t} \sum_{m=a}^{r a} S_{a, m}^{G} \mathbf{1} \mathbf{l}\right) /(1+d)_{-}^{\bar{m}_{-} a}$

$\boldsymbol{M}=$ Male, $\boldsymbol{F}=$ Female, $\boldsymbol{G}=$ Gender $\boldsymbol{t}=$ year, $\boldsymbol{a}=$ age at time $t, \boldsymbol{r} \boldsymbol{a}=$ retirement age, ara $=$ average age for retirees, $\boldsymbol{m}=$ age between current age a and retirement age ra, $\boldsymbol{n}=$ age between retirement age ra and the maximum age, $85, \boldsymbol{w}=$ wives, $\boldsymbol{O}=$ orphans, $\boldsymbol{d}=$ personal discount rate, $\boldsymbol{g}=$ growth rate of real reference income, $\boldsymbol{g a}=$ growth rate of real annuities, $\boldsymbol{W}=$ number of employers, $\boldsymbol{P}=$ LFPR adjustment factor, $\boldsymbol{C}=$ ratio of active insured employment to total employment, $\boldsymbol{\theta}=$ tax factor, $\boldsymbol{Y}=$ reference income, $\boldsymbol{A} \boldsymbol{V} B=$ per retiree average old-age benefit, $\boldsymbol{A B D}=$ per retiree average disability benefit, $\boldsymbol{A B S W}=$ per retiree (wives) average survivors benefit, $\boldsymbol{A B S O}=$ per retiree (orphans) average survivors benefit $\boldsymbol{S}_{(a, m)}=$ survival probability of a person who lives up to age $m$, given that she/he lived up to age $a, \boldsymbol{b} \boldsymbol{f}=$ benefit factor, $\boldsymbol{N}=$ number of old-age beneficiaries, $\boldsymbol{s} \boldsymbol{r}=\%$ of male married, $\boldsymbol{B R}=$ discount ratio for benefits passed from worker or retirees to survivors. 
5. Results: The first thing to observe is the magnitude of the SSW series relative to other forms of household wealth and NPrvDI as seen in Table 6 below. This observation reinforces the argument that the social security wealth could be an important determinant in saving and consumption studies.

Table 6: Total Wealth in Financial Assets, Housing and SSW ${ }^{33}$ with NPrvDI (Million TL in 1987 Prices)

\begin{tabular}{lccccc}
\hline & TFA $^{34}$ & Housing $^{35}$ & SSWG & SSW & NPrvDI \\
$\mathbf{1 9 7 0}$ & $7,588,518$ & $32,700,333$ & $54,350,527$ & $43,721,351$ & $25,592,525$ \\
$\mathbf{1 9 7 5}$ & $10,806,548$ & $41,781,557$ & $89,508,490$ & $69,086,105$ & $33,269,315$ \\
$\mathbf{1 9 8 0}$ & $9,674,345$ & $56,696,805$ & $63,905,043$ & $33,945,697$ & $42,029,239$ \\
$\mathbf{1 9 8 5}$ & $20,075,898$ & $63,750,469$ & $62,728,296$ & $24,296,819$ & $45,873,753$ \\
$\mathbf{1 9 9 0}$ & $26,996,582$ & $88,709,913$ & $111,574,201$ & $65,316,832$ & $67,179,895$ \\
$\mathbf{1 9 9 5}$ & $46,704,601$ & $128,391,319$ & $103,123,054$ & $49,536,263$ & $84,157,732$ \\
$\mathbf{1 9 9 6}$ & $61,819,289$ & $135,536,058$ & $171,916,203$ & $119,046,643$ & $86,040,622$ \\
$\mathbf{1 9 9 7}$ & $69,998,934$ & $152,101,623$ & $231,487,100$ & $160,536,942$ & $92,590,536$ \\
$\mathbf{1 9 9 8}$ & $75,985,989$ & $160,030,906$ & $277,262,042$ & $185,039,302$ & $102,044,735$ \\
$\mathbf{1 9 9 9}$ & $96,063,696$ & $159,652,714$ & $292,422,907$ & $198,503,687$ & $102,748,644$ \\
$\mathbf{2 0 0 0}$ & $95,036,365$ & $159,160,494$ & $276,903,910$ & $185,179,981$ & $103,808,861$ \\
$\mathbf{2 0 0 1}$ & $146,103,010$ & $165,728,972$ & $270,810,987$ & $198,497,777$ & $100,472,296$ \\
$\mathbf{2 0 0 2}$ & $126,833,322$ & $158,074,788$ & $297,929,986$ & $236,761,695$ & $98,286,544$ \\
$\mathbf{2 0 0 3}$ & $117,491,297$ & $166,061,466$ & $342,736,721$ & $283,310,716$ & $105,211,662$
\end{tabular}

The second important point is that SSWG and SSW series overweigh NPrvDI most of the time. There are two major reasons for this increasing trend in the SSW series: first, the participation rate to the public social security system for the workers exponentially increases over the years, and second, even though the increase in the number of covered workers is high, the number of beneficiaries in the system even grows faster than the active contributors. After 1992, the minimum retirement age requirement was removed. This elimination of minimum age requirement led to average age retirement ages as young as 47 years of age in SSK and 48 years of age in ES, the lowest in the world (The World Bank Country Economic Memorandum, 2000). ${ }^{36}$ As seen Table 7 below, the number of beneficiaries increases $1944 \%$ whereas the number of individuals who contribute to the system increases only 437\% between 1970 and 2003.

\footnotetext{
${ }^{33} \mathrm{SSW}$ series are calculated by $3 \%$ discount rate, $2 \%$ growth rate in income (not in annuities) with "current benefit factor" method.

${ }^{34}$ Total Financial Assets (TFA) is calculated by State Planning Organization (SPO) for the entire economy regardless of who holds them.

${ }_{35}^{35}$ Housing wealth is an approximation, see Appendix.

${ }^{36}$ Minimum ages were very low even before 1999 . The average minimum retirement ages for OECD countries are 64.4 for men and 63.9 for women in 2002 (OECD 2005).
} 
Table 7: Turkish Public Social Security Participants

\begin{tabular}{|c|c|c|c|c|c|}
\hline & $\begin{array}{l}\text { Total Active } \\
\text { Contributors }\end{array}$ & $\begin{array}{c}\% \\
\text { Growth }\end{array}$ & $\begin{array}{c}\text { Total } \\
\text { ODD Beneficiaries }\end{array}$ & $\begin{array}{c}\% \\
\text { Growth }\end{array}$ & $\begin{array}{c}\text { Dependency } \\
\text { Ratio }\end{array}$ \\
\hline 1970 & $2,172,330$ & & 331,399 & & 6.56 \\
\hline 1975 & $3,779,893$ & $74 \%$ & 625,657 & $89 \%$ & 6.04 \\
\hline 1980 & $4,708,044$ & $117 \%$ & $1,240,214$ & $274 \%$ & 3.80 \\
\hline 1985 & $5,890,253$ & $171 \%$ & $1,975,399$ & $496 \%$ & 2.98 \\
\hline 1990 & $7,990,454$ & $268 \%$ & $2,928,240$ & $784 \%$ & 2.73 \\
\hline 1995 & $9,284,849$ & $327 \%$ & $4,107,168$ & $1139 \%$ & 2.26 \\
\hline 2000 & $10,994,287$ & $406 \%$ & $5,842,170$ & $1663 \%$ & 1.88 \\
\hline 2001 & $10,674,982$ & $391 \%$ & $6,187,382$ & $1767 \%$ & 1.73 \\
\hline 2002 & $11,137,196$ & $413 \%$ & $6,476,932$ & $1854 \%$ & 1.72 \\
\hline 2003 & $11,663,428$ & $437 \%$ & $6,774,131$ & $1944 \%$ & 1.72 \\
\hline
\end{tabular}

We applied three different perception methods for benefit and tax factors. As Figure 5 below shows, because of the strong trends in both factors, the SSW series calculated with constant average benefit and tax factors substantially underestimate SSW before 1981 and overestimate it after 1981 relative to other perception methods.

Figure 5: Per Capita SSWG Series with Different Perceptions ${ }^{37}$

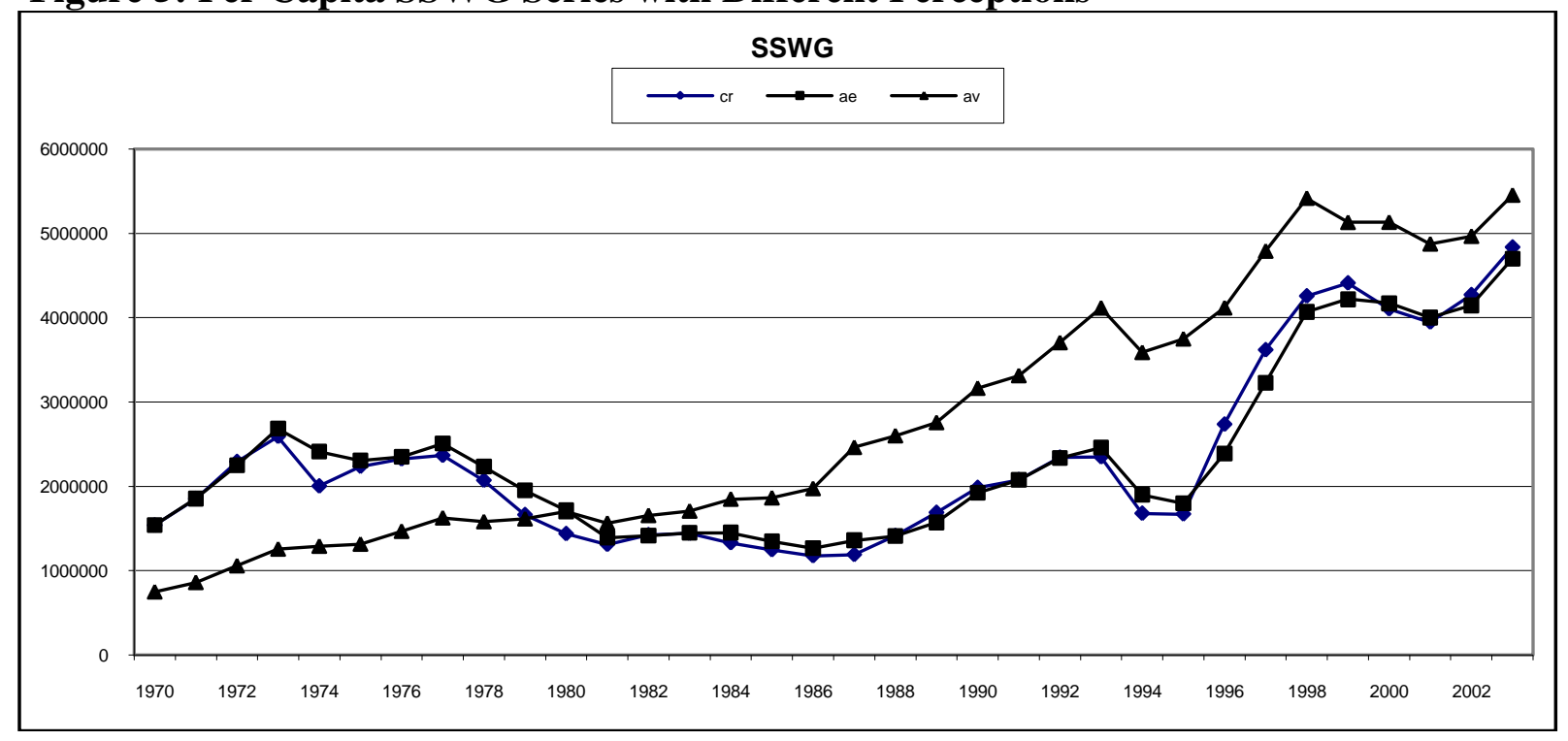

As noted before, SSW is a proxy for the perception of future public social security entitlements. Many improvements can be made to have more "precise" SSW series. We did not take the health benefits into account for example. Likewise, in calculating SSWG for beneficiaries, we applied gender based average ages. Additional micro level data and information can be used to make the SSW series more precise. However, how appropriate the improvements are depends on the extent to which they are perceived and anticipated by people. We are not looking for a simulation that provides exact actuarial values of social security wealth in Turkey.

${ }^{37} a v$, average factors, is the first perception method; $a e$, adaptive expectations, is the second; and $c r$, current is the third. 
In principle, if the social security wealth series represent the perception of the people about the magnitude of the complex actuarial future benefits and tax liabilities in Social Security, this would be satisfactory for our purposes. Instead of making more fine-tunings in our SSW series, we look at our assumptions more critically.

We consider the SSW series calculated with $3 \%$ discount rate, $2 \%$ growth rate and the "current" benefit and tax factors as our main SSW series. The detailed tables and graphs for these SSW series are given at the end.

\section{Generational Fairness of the Turkish Social Security System}

In addition to its aging population, ${ }^{38}$ Turkey has an additional challenge: it has a very low labor force participation rate and widespread informal sectors. ${ }^{39}$ For the last seven years, there have been four parametric reforms in Turkey, all of which have been designed to phase-in gradually. In other words, only new generations face the full adjustment cost to achieve the long-run financial sustainability of the system. The Turkish social security system is and has been a Ponzi scheme for a long time: unpaid liabilities for coming generations have been piling up to maintain the generosity of the system. What is the magnitude of this intergenerational wealth distribution in the last forty years? The answer to this question is important because it will reveal the cost of this generational injustice in terms of distorted economic dynamics in Turkey.

One way to evaluate the generational fairness of a PAYG system is to look at lifetime expected wealth increments and losses created by the system for different age cohorts at any given time. From a household's perspective, SSW can be anticipated on the rest-of-the-life basis. In other words, already paid contributions and benefits can be considered as "sunk" and what Social Security offers is evaluated based on the future benefits and taxes at any given time. If this anticipation is valid, as a person ages, his/her SSW increases. ${ }^{40}$ In this sense, aggregated series reflect the total value of SSW for all age groups in any given year and truncate the early years. Since contributions paid in the past are excluded from the calculation, as the share of beneficiaries (retirees) in the total population covered by Social Security expands, the total value of SSW gets bigger. As seen in Table 7 above, the number of retirees is exponentially increasing and surpassing the number of contributors. Beneficiaries do not have tax liabilities but benefit expectations. In the absence of a required minimum retirement age, the rapid growth in the number of beneficiaries explodes the aggregate SSW. As a result, both the cumulative deficit of the Turkish PAYG system based on actuarial projections (Table 8 - below) and the per capita expected SSW (Figure 5 - above) are increasing together after 1995. If the increase in the average expected SSW is a result of the increase in the number of retirees and the system is only able to honor these promises in the future by increasing unpaid liabilities for unborn generations, new entrants of the Turkish social security system should have decreasing SSW expectations. This is the question that we will investigate in the rest of the paper.

The magnitude of a PAYG system's generational imbalance can be measured by the net present value of future revenues and payments of the system for all current and coming

\footnotetext{
${ }^{38}$ Even though Turkey has a relatively younger population, the ratio of the population of 65 years old and over to ages 0-64 is expected to increase from 5\% to $14 \%$ in 35 years. The same ratio will be reached by 2020 in the US after 75 years.

${ }^{39}$ Labor force participation rate in Turkey is less than $50 \%$.

${ }^{40}$ This partly explains the mystery of why people with modest or even negative lifetime SSW values could still support Social Security.
} 
generations. The total deficit of Turkish social security system financed by public borrowing (and seigniorage) is almost 4.5\% of GDP in 2004. Between 1990 and 2003, the present value of the total resources used to finance the deficit of the social security system is almost equal to the total GNP created in $2003 .^{41}$ The system's generosity and unsustainable financial structure can be seen in Table (8) below, which uses the parameters of the system in 1996.

Table 8: Main Results of Actuarial Projections

\begin{tabular}{|c|c|c|c|c|}
\hline & $\begin{array}{c}\text { Reverse } \\
\text { Dependency } \\
\text { Ratio }\end{array}$ & $\begin{array}{c}\text { Replacement } \\
\text { Rate }\end{array}$ & $\begin{array}{c}\text { Deficit } \\
\% \text { of GDP }\end{array}$ & $\begin{array}{c}\text { Cumulative } \\
\text { Deficit } \\
\% \text { of GDP }\end{array}$ \\
\hline 1995 & $55 \%$ & $95 \%$ & 1.80 & 1.80 \\
\hline 2000 & $65 \%$ & $96 \%$ & 2.70 & 19.70 \\
\hline 2005 & $71 \%$ & $97 \%$ & 3.40 & 32.10 \\
\hline 2010 & $80 \%$ & $99 \%$ & 4.30 & 50.20 \\
\hline 2020 & $90 \%$ & $100 \%$ & 5.60 & 97.30 \\
\hline 2030 & $96 \%$ & $100 \%$ & 7.00 & 153.90 \\
\hline 2050 & $115 \%$ & $101 \%$ & 10.10 & 316.00 \\
\hline
\end{tabular}

Sources: ILO, IMF, OECD, the World Bank, and the Ministry of Labor Affairs.

The projected deficit for the system in 2005 underestimated the actual by almost $1 \%$ of GDP and that projected for 2010 was realized by $2004 .{ }^{42}$ Even though it is clear from the above table that the PAYG system in Turkey has been and will be redistributive from younger to older generations, the magnitude and the time path of this redistribution for different age cohorts have to be analyzed. ${ }^{43}$

Unlike aggregate SSW series, in which only future taxes are taken into the calculation and past taxes could be considered as 'sunk', individual expected SSW series for different age cohorts are calculated at any time as a difference between the present values of incurred and expected lifetime contributions and benefits. Because the information on historical wage series based on age, cohort, and gender is not easily available or estimating them entails many sensitive assumptions, some researchers use hypothetical simulations for measuring the generational fairness of Social Security. ${ }^{44}$ In these studies, arbitrary income levels for different genders are chosen for a typical individual (say at the age of 20 or 25) in any given year and deflated for older age cohorts and inflated for coming generations as to reflect the wage differences between age cohorts. A similar study done by Brook and Whitehouse (2006) is the only attempt to show the distributional characteristics of the Turkish PAYG system. Their simulation is based on the eligibility of a generic worker to specific annuitization rules and minimum age requirements of the system for different age cohorts. In their study, the system's generational generosity is measured by gross pension wealth (PW) and benefit/cost ratios (BCR)

\footnotetext{
41 "Proposal for Reform in the Social Security System" (2004), Ministry of Labor and Social Security

${ }^{42}$ The longevity, which is 69 years in 2005, is expected to be 79 years in 2045 in Turkey.

${ }^{43}$ In reading the above table, not only demographic projections but also other inefficiencies in the system should be taken into considerations. As underlined in Section 3, the weak link between contributions and benefits (for example, in SSK, pensions were linked to wages paid in the last five years and the same link was even worse in ES and Bag-Kur: only the last year's wages were used to calculate pensions), the high informal employment due to relatively high statutory contribution rates, the lack of automatic indexation of the contribution ceiling under high inflation conditions, and the low premium collection rates because of administrative inefficiencies are also the major reasons behind the soaring deficit.

${ }^{44}$ Some important studies are cited in Section 2.
} 
for an average earner of SSK (Social Security Institution for wage earners) in different age cohorts. In the absence of reliable information on historical wage differences among age cohorts and genders, they use an arbitrary income level to calculate past and present contributions for each age cohort. To our knowledge, they use the same income level for each age cohort and therefore their calculations do not reflect cohort specific differences in income. Because it expands the contribution period and reduces the duration of benefits receipt, the most important factor that affects PW and BCR in their calculation is the minimum retirement age. ${ }^{45}$ Generally speaking, though, PW and BCR decline significantly only for the age cohorts born after 1980, since the fundamental parametric reforms raise the minimum age gradually and went into effect after 2001.

We do not intent to make an actuarial projection similar to those done by ILO (1995), OECD (2005), and IMF (2000) for the Turkish PAYG system. The information in Table 8 above that we compiled from different resources is enough to show the severity of intergenerational redistributions caused by the generosity of the system. ${ }^{46} \mathrm{We}$ are rather interested in finding the variation in the expected SSW among new entrants in different years. These expectations could change as a new member of the system matures. However, as long as the assumptions are consistent for each age cohort, we believe that the trend or the variation in SSW expectations for different age cohorts should give a rough idea about the distributive feature of the system. There are three important points that differentiate our study from actuarial simulations:

1. Our cohort-specific SSW and implicit rate of return (IRR) values represent perceptions that each new entrant in each age cohort may have from Social Security and not the actuarial realization that a new entrant may end up with at the end of his/her life. Therefore, the SSW that a representative individual in each age cohort might expect would be different than what actually he/she will be entitled at the end.

2. Values based on actuarial realization, such as PW and BCR, vary only by the "eligibility" of each individual to the specifics of the program. However, since there are no effective minimum age requirements before 2000 in Turkey, each hypothetical individual in PW and BCR calculations has the same retirement age assumption, which had remained the same until 2000. ${ }^{47}$ Therefore, actuarial realizations of PW and BCR before 2000 cannot reveal any information about the difference in perceptions of the SSW 'deal' for different age cohorts.

3. In Turkey, between 2000 and 2006 there are three different reforms that changed the minimum age requirements and other fundamental parameters of the system.

Besides, all reforms have been amended by the Supreme Court. Therefore, it is more likely that people's expectations on SSW may significantly deviate from what they will ultimately be entitled after 2000 .

In finding anticipated SSW and the implicit rate of return for a representative new member of the system for different years and genders, we look at a typical worker entering the

\footnotetext{
45 They use OECD pension models as described in a study published by OECD (2005). BCR is the ratio between the pension wealth at retirement and the sum of contributions paid into the system (both expressed in present value terms)

${ }^{46}$ However, the rapid growth of the system's deficit is resulted from not only the system's unsound actuarial structure but also its deep administrative inefficiencies, unofficial workforce and so on.

${ }^{47}$ A comparison of the trends in SSW across age cohorts by two methods gives a similar result: it is declining.
} 
labor force at the age of 17 and expecting to retire at the age of 55. Unlike the Brook and Whitehouse's study (2006), we assume an average constant minimum retirement age that each new member would anticipate. Further, we do not use the systems' frequently changing specifications for annuitizations. In this sense, our simulations are not directly sensitive to parametric changes in the system and represent aggregate expectations of new members on social security wealth and not actuarial values that different age cohorts are entitled. The assumptions and the simulation methods are the same as previously explained in Section 4 and the results are given in Table 9 below.

Table 9: Expected Implicit Rate of Return (IRR) for New Members (TL in 1987 Prices)

\begin{tabular}{crrrrr}
$\begin{array}{c}\text { Males } \\
\text { Birth }\end{array}$ & Year at 17 & P.V of Benefits & P.V. of Taxes & SSW & \multicolumn{1}{c}{ IRR } \\
$\mathbf{1 9 5 3}$ & $\mathbf{1 9 7 0}$ & $3,606,650,457$ & $1,825,975,329$ & $1,780,675,128$ & $98 \%$ \\
$\mathbf{1 9 5 8}$ & $\mathbf{1 9 7 5}$ & $5,265,707,462$ & $3,647,549,968$ & $1,618,157,494$ & $44 \%$ \\
$\mathbf{1 9 6 3}$ & $\mathbf{1 9 8 0}$ & $3,048,514,093$ & $2,583,551,520$ & $464,962,573$ & $18 \%$ \\
$\mathbf{1 9 6 8}$ & $\mathbf{1 9 8 5}$ & $2,577,861,720$ & $2,917,518,656$ & $(339,656,936)$ & $-12 \%$ \\
$\mathbf{1 9 7 3}$ & $\mathbf{1 9 9 0}$ & $3,555,285,563$ & $5,138,872,792$ & $(1,583,587,230)$ & $-31 \%$ \\
$\mathbf{1 9 7 8}$ & $\mathbf{1 9 9 5}$ & $2,735,679,632$ & $4,022,124,466$ & $(1,286,444,833)$ & $-32 \%$ \\
$\mathbf{1 9 8 3}$ & $\mathbf{2 0 0 0}$ & $4,695,027,081$ & $8,018,815,049$ & $(3,323,787,968)$ & $-41 \%$ \\
$\mathbf{1 9 8 4}$ & $\mathbf{2 0 0 1}$ & $4,432,429,430$ & $7,987,741,556$ & $(3,555,312,126)$ & $-45 \%$ \\
$\mathbf{1 9 8 5}$ & $\mathbf{2 0 0 2}$ & $4,952,771,478$ & $8,437,523,249$ & $(3,484,751,772)$ & $-41 \%$ \\
$\mathbf{1 9 8 6}$ & $\mathbf{2 0 0 3}$ & $5,660,229,224$ & $10,042,925,509$ & $(4,382,696,285)$ & $-44 \%$ \\
Females & & & & & \\
Birth & Year at 17 & $\mathbf{P . V ~ o f ~ B e n e f i t s ~}$ & P.V. of Taxes & SSW & IRR \\
$\mathbf{1 9 5 3}$ & $\mathbf{1 9 7 0}$ & $995,219,372$ & $455,949,939$ & $539,269,433$ & $118 \%$ \\
$\mathbf{1 9 5 8}$ & $\mathbf{1 9 7 5}$ & $1,244,271,207$ & $769,338,968$ & $474,932,239$ & $62 \%$ \\
$\mathbf{1 9 6 3}$ & $\mathbf{1 9 8 0}$ & $758,720,899$ & $578,245,901$ & $180,474,998$ & $31 \%$ \\
$\mathbf{1 9 6 8}$ & $\mathbf{1 9 8 5}$ & $639,094,167$ & $650,459,820$ & $(11,365,653)$ & $-2 \%$ \\
$\mathbf{1 9 7 3}$ & $\mathbf{1 9 9 0}$ & $1,091,448,917$ & $1,435,145,981$ & $(343,697,063)$ & $-24 \%$ \\
$\mathbf{1 9 7 8}$ & $\mathbf{1 9 9 5}$ & $877,644,529$ & $1,204,728,587$ & $(327,084,058)$ & $-27 \%$ \\
$\mathbf{1 9 8 3}$ & $\mathbf{2 0 0 0}$ & $2,849,924,052$ & $3,892,975,717$ & $(1,043,051,665)$ & $-27 \%$ \\
$\mathbf{1 9 8 4}$ & $\mathbf{2 0 0 1}$ & $2,599,405,050$ & $3,679,470,756$ & $(1,080,065,706)$ & $-29 \%$ \\
$\mathbf{1 9 8 5}$ & $\mathbf{2 0 0 2}$ & $2,775,039,747$ & $3,760,828,690$ & $(985,788,943)$ & $-26 \%$ \\
$\mathbf{1 9 8 6}$ & $\mathbf{2 0 0 3}$ & $3,415,052,228$ & $4,798,555,499$ & $(1,383,503,271)$ & $-29 \%$
\end{tabular}

As stressed before, in our analysis, the magnitude of the anticipated 'deal' from Social Security is not important for specific cohorts and could be modified by increasing the starting age to work from 17 to, say, 21. Before the reform in 1999, if one of the following two minimum retirement conditions is satisfied, an individual would be entitled to retire: (1) 25 years in the system and 15 years minimum contributions, or (2) age 55 and minimum 15 years contributions. For that reason, if an individual becomes a member of Social Security at the age of 17 and pays at least 15 years in the system, he could retire at the age of 43 . If we take this case as an example, paying only 15 years and receiving benefits after 43, the IRR and SSW would be positive and substantial for that individual before 1999. The pension model by OECD (2005) that compares generosity of the systems across the member countries uses "minimum requirement" rules for retirement eligibilities and calculates PW and BCR for an hypothetical individual. Therefore, according to both studies, OECD (2005) and Brook and Whitehouse (2006), the Turkish social security is the champion of generosity among the OECD countries, 
with very high $\mathrm{PW}$ and $\mathrm{BCR}$.

In our simulations, we assume that people with the available information take the current factors (benefit and tax) as their expectations. The values of SSW and IRR are directly linked to these factors. However, when we use moving averages of tax and benefit factors, the trend in IRR becomes very similar to one in Figures 6 below.

Figure 6: Trend in Expected IRR for New Members (Males)

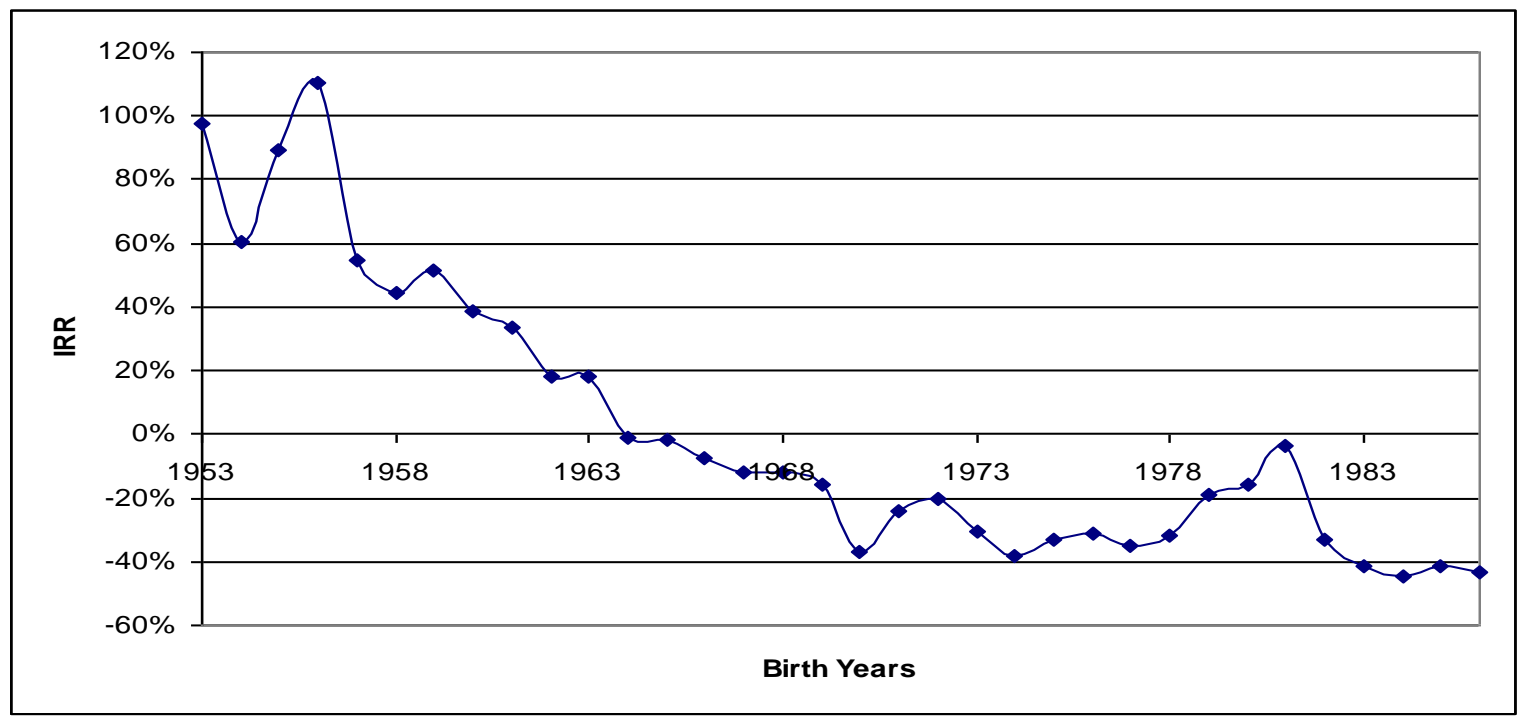

The trend in IRR for both genders ${ }^{48}$ shows that new members of the system in every following age cohort anticipate a lower return for their social security contributions. Even though our simulation indicates a short period of rise in expectations between 1990 and 1996, this escalation is mainly caused by populist policies during a politically unstable period. There are three parametric reforms and several amendments after 2000 that increase the required minimum retirement age for new participants and adjusts the annuitization. In addition to the fact that all these changes have occurred in as short a period as four years, many initial amendments have been canceled by the Supreme Court and replaced by new ones. Consequently, it is hard to speculate about how people formed their expectations in this "confusing" period about Social Security. Although we incorporate the changes in age requirements into our simulations by increasing the retirement age from 55 to 58 and later to 60 for new members, we do not adjust the way that benefits are calculated in our simulations. ${ }^{49}$ Our results show that the decreasing trend in SSW expectations for new generations is consistent with the fact that the Turkish PAYG system is only able to honor generous promises to current generation by increasing unpaid liabilities for coming generations. It is safe to say that the current system creates a severe generational injustice in the eyes of Turkish people.

\footnotetext{
${ }^{48}$ The IRR values are significantly better for females. The fundamental reason for this difference is that females have significantly higher survival rates.

${ }^{49}$ The new calculation method for annuities is rather complex. Since the change was in effect after 2001, we only changed the minimum retirement age for new members and kept our fundamental functions the same to calculate first annuities based on benefit factor expectations. This negligence has a very little effect on the aggregate SSW series since the change covers only three years after 2001 and the share of new members in the total covered individuals is less than $5 \%$.
} 


\section{Conclusion}

Turkey has been undergoing the most substantial recovery in its history after two subsequent economic crises in 1999 and 2001. The reforms led by IMF and the World Bank aim at structural changes in the country's traditional populist fiscal policies. The essential part of these reforms is Social Security and Health Care. Turkey is the most generous country in terms of social security provisions in the OECD region and there is no actuarial basis in many public pension practices. There are numerous studies in Turkey that investigate this problem and possible solutions. While some researchers have been suggesting structural reforms, the majority of proposed solutions are based on parametric adjustments in the system, perhaps because of their political feasibility. However, there is no single study to measure the aggregate magnitude of wealth in financial terms generated by the Turkish Social Security relative to other nonpension wealth in the economy for any given year. Studies that quantify the value of Social Security that a typical individual across generations may anticipate to gain or lose in different years are limited. Has this expected "deal" from Social Security been declining or increasing from a representative household's perspective in different age cohorts and genders in Turkey? This is an important question not only because expectations in Social Security directly affect economic dynamics, but also the pay-as-you-go nature of the systems constitutes cumulating generational inequality and a Ponzi scheme, which is not sustainable. There are many researchers around the world calculating aggregate and generational values created by Social Security, mostly for developed countries.

This study is the first of its kind for an emerging country, Turkey. By putting many assumptions, parameters, demographics, survival rates, and complex rules together in a computer simulation, we create the aggregate social security wealth series for the period between 1970 and 2003. These series show that the expected SSW is the biggest part of household wealth and therefore should not be ignored by economists investigating a range of issues such as consumption and saving in Turkey ${ }^{50}$. Because they are supposed to indicate the magnitude of the current aggregate wealth for the entire economy, we use the rest-of-the-life method and consider the past contributions and benefits as "sunk" in aggregate SSW simulations. While this method seems valid in calculating aggregate series, we use SSW simulations that cover the entire lifetime for finding the "deal" and the anticipated implicit rate of return of a new participant to the system in different age cohorts. How an individual would perceive this "deal" at any period of his/her life is an open question. Calculations covering the entire lifetime require very complex techniques and periodic updates through time for an individual. However, if we compare the new participants' initial expectations, then the resulting trend for coming generations should be indicative of the generational fairness of the system. Our study shows that, the implicit expected rate of return for different age-cohorts has a significant and declining trend in Turkey between 1970 and 2003.

These results suggest that the magnitude of the aggregate social security wealth and the massive distributional impact of Social Security on wealth are important factors for investigations and future reforms seeking for solutions to the Turkish Social Security system.

\footnotetext{
${ }^{50}$ Aggregate SSW series are used to investigate the saving effects of social security in time-series and cross-section studies by Aydede (2006, 2006a).
} 


\begin{tabular}{|c|c|c|c|c|c|c|c|}
\hline & $\begin{array}{c}\text { \# of } \\
\text { Buildings }\end{array}$ & $\begin{array}{c}\text { Total value } \\
\text { YTL }\end{array}$ & $\begin{array}{c}\text { \#of } \\
\text { Dwelling } \\
\text { Units }\end{array}$ & $\begin{array}{c}\text { Per Dwelling } \\
\text { Value YTL }\end{array}$ & $\begin{array}{c}\text { Stock of } \\
\text { Dwellings }\end{array}$ & $\begin{array}{l}\text { Total Housing } \\
\text { (Current YTL) }\end{array}$ & $\begin{array}{c}\text { Total Housing } \\
\text { Constant YTL } \\
1987=100\end{array}$ \\
\hline 1970 & 35,299 & 2,381 & 71,589 & 0.03 & $8,097,432$ & 269,280 & $44,230,162$ \\
\hline 1971 & 35,458 & 2,676 & 72,816 & 0.04 & $8,170,248$ & 300,298 & $41,966,531$ \\
\hline 1972 & 43,822 & 3,464 & 88,231 & 0.04 & $8,258,479$ & 324,235 & $40,724,831$ \\
\hline 1973 & 43,192 & 4,506 & 96,163 & 0.05 & $8,354,642$ & 391,469 & $40,365,458$ \\
\hline 1974 & 39,072 & 5,906 & 84,199 & 0.07 & $8,438,841$ & 591,963 & $47,530,223$ \\
\hline 1975 & 44,122 & 9,544 & 97,431 & 0.10 & $8,536,272$ & 836,213 & $55,507,201$ \\
\hline 1976 & 45,141 & 10,536 & 102,110 & 0.10 & $8,638,382$ & 891,291 & $51,410,212$ \\
\hline 1977 & 53,937 & 15,176 & 119,409 & 0.13 & $8,757,791$ & $1,113,043$ & $51,885,198$ \\
\hline 1978 & 52,273 & 35,405 & 120,615 & 0.29 & $8,878,406$ & $2,606,165$ & $82,830,576$ \\
\hline 1979 & 53,284 & 64,489 & 124,297 & 0.52 & $9,002,703$ & $4,670,845$ & $84,480,189$ \\
\hline 1980 & 58,970 & 116,739 & 139,207 & 0.84 & $9,141,910$ & $7,666,419$ & $73,717,907$ \\
\hline 1981 & 53,257 & 131,770 & 118,778 & 1.11 & $9,260,688$ & $10,273,625$ & $68,575,548$ \\
\hline 1982 & 50,261 & 161,315 & 115,986 & 1.39 & $9,376,674$ & $13,041,200$ & $67,887,029$ \\
\hline 1983 & 50,719 & 228,738 & 113,453 & 2.02 & $9,490,127$ & $19,133,477$ & $78,886,397$ \\
\hline 1984 & 54,187 & 362,184 & 122,580 & 2.95 & $9,612,707$ & $28,402,396$ & $78,996,221$ \\
\hline 1985 & 49,380 & 544,192 & 118,205 & 4.60 & $9,730,912$ & $44,799,152$ & $81,409,828$ \\
\hline 1986 & 67,528 & $1,234,924$ & 168,597 & 7.32 & $9,899,509$ & 72,511,037 & $96,883,443$ \\
\hline 1987 & 76,106 & $1,919,741$ & 191,109 & 10.05 & $10,090,618$ & $101,362,966$ & $101,362,966$ \\
\hline 1988 & 78,787 & $4,038,420$ & 205,485 & 19.65 & $10,296,103$ & $202,350,491$ & $119,486,420$ \\
\hline 1989 & 88,795 & $7,530,262$ & 250,480 & 30.06 & $10,546,583$ & $317,065,379$ & $106,697,713$ \\
\hline 1990 & 89,217 & $11,165,964$ & 232,018 & 48.13 & $10,778,601$ & $518,724,747$ & $110,313,008$ \\
\hline 1991 & 87,506 & $21,557,156$ & 227,570 & 94.73 & $11,006,171$ & $1,042,588,009$ & $139,569,473$ \\
\hline 1992 & 100,090 & $45,639,626$ & 268,886 & 169.74 & $11,275,057$ & $1,913,782,798$ & $156,482,649$ \\
\hline 1993 & 96,694 & $77,874,115$ & 269,694 & 288.75 & $11,544,751$ & $3,333,545,781$ & $162,467,195$ \\
\hline 1994 & 95,469 & $140,341,023$ & 245,610 & 571.40 & $11,790,361$ & 6,736,986,997 & $159,038,163$ \\
\hline 1995 & 91,548 & $255,289,420$ & 248,946 & $1,025.48$ & $12,039,307$ & $12,346,082,266$ & $155,687,653$ \\
\hline 1996 & 99,257 & $501,132,881$ & 267,306 & $1,874.75$ & $12,306,613$ & $23,071,867,499$ & $163,595,922$ \\
\hline 1997 & 100,446 & $1,030,175,494$ & 277,056 & $3,718.29$ & $12,583,669$ & $46,789,774,667$ & $182,757,994$ \\
\hline 1998 & 86,770 & $1,605,674,843$ & 238,958 & $6,719.49$ & $12,822,627$ & $86,161,460,131$ & $191,565,907$ \\
\hline 1999 & 82,849 & $2,204,068,446$ & 215,613 & $10,222.34$ & $13,038,240$ & $133,281,268,717$ & $190,492,432$ \\
\hline 2000 & 86,279 & $3,662,766,998$ & 245,155 & $14,940.62$ & $13,283,395$ & $198,462,124,714$ & $189,230,514$ \\
\hline 2001 & 81,568 & $5,738,525,760$ & 243,464 & $23,570.33$ & $13,526,859$ & $318,832,480,159$ & $196,372,214$ \\
\hline 2002 & 56,029 & $5,159,938,602$ & 161,491 & $31,951.86$ & $13,688,350$ & $437,368,320,676$ & $186,895,082$ \\
\hline 2003 & 51,834 & $6,540,051,331$ & 162,906 & $40,146.17$ & $13,851,256$ & $556,074,838,629$ & $195,917,791$ \\
\hline
\end{tabular}

The numbers for buildings and dwelling units are based on occupancy permits, which are taken from the State Institutes of Statistics (SIS) together with their values. In order to find the total stock of dwelling units for each year, the total population is divided by 4.362 to find the total number of households in 1970 and the number of new dwelling units is added to this number $(8,097,432)$ for the subsequent years. The number ' 4.362 ' is chosen to find the same number of households in 1985, which is found by SIS 9,730,018. The other checkpoint for this approximation is in 1990, which is $11,188,636$ and not consistent with what we found.

The main reason for this discrepancy is that the number of total occupancy permits is not a correct measure to find each year's added dwelling units due to the existence of illegal occupations and high rural population in which there is no need for this permit. Therefore the total number of dwelling units underestimates the correct number each year. However, since the 
price of newly added dwelling units is taken as the average price of all dwelling units, the total value of dwelling units probably overestimates the true value of housing wealth. Even though these two factors may offset each other, it is difficult to speculate on the correct measure of housing wealth in Turkey. 


\section{Benefit and Tax Factors}

\section{SSK}

The number of beneficiaries, the amount of benefits (Old-age, Disability and Death - ODD) are from special tables sent by SSK. The number of contributors and incurred contributions are from SIS. Average ages and other related other information are from SSK's Web page.

\section{ES}

The number of beneficiaries, contributors and the amount of benefits (Old-age, Disability and Death - ODD) contributions are from "Statistical Indicator 1923-2002" SIS. Average ages and related other information are from ES's Web page.

\section{Bag-Kur}

The number of beneficiaries, contributors and the amount of benefits (Old-age, Disability and Death - ODD) contributions are from "Statistical Indicator 1923-2002" SIS and also sent by BK. Average ages and other related information are from BK's Web page.

\section{Reference Income}

As explained in the paper, we used Net Private Disposable income (NPrvDI), which is constructed by the following identity:

$$
N \operatorname{PrvDI}=C+I-G S+F S-C o C
$$

The data on household consumption (C), investment (I) and Consumption of Capital (CoC) are from the OECD.

Government saving (GS) is calculated by the State Planning Organization (SPO) since 1975 under the title of "Public Sector General Balance". For the years between 1970 and 1974, GS is estimated by taking $50 \%$ of the total government spending in corresponding years. This is because the same ratio is approximately 50\% for the years between 1975 and 1985.

Foreign Saving (or resources) is taken from the table, "General Macro Balance of the Economy", generated by SPO for the period between 1987 and 2003. For earlier years Net Export (NX) plus Net Foreign Income from Abroad (NFI) is calculated by using the WDI database.

Gross private disposable income is calculated by SPO since 1987 using the same method. We checked whether or not there is an inconsistency between my and SPO's numbers and found some differences between the two series. Since we use national accounts by expenditure, these differences mainly come from the statistical error (discrepancy) between two different national account methods: by production and by expenditure. 


\section{Labor Force Demographics}

The total population, age and gender based labor force, employment numbers and marriage ratios are taken from the database created by the State Institute of Statistics (SIS) for the years between 1987 and 2003. For the years before 1988, we used Bulutay (1995) and ILO statistics.

\section{$\underline{\text { Survival Probabilities }}$}

In order to find survival probabilities, we used ADST 49-51 as the mortality table from the US. This table is extensively used by private pension companies and we took it from Aviva Life Insurance in Turkey. 
Altamarinta, M. (1999). Argentina's Generational Accounts: Is the Convertibility Plans' Fiscal Policy Sustainable. In Auerbach, A. Et al., Ed., "Generational Accounting around the World" by NBER. The University of Chicago Press.

Ando, Albert and Modigliani, F. (1963). The Life Cycle Hypothesis of Saving: Aggregate Implications and Tests, The American Economic Review, Vol.53.

Auerbach, A. Et al. (1999). Generational Accounting around the World. NBER. The University of Chicago Press.

Auerbach, A. Et al. (1991). Generational Accounts: A Meaningful Alternative to Deficit Accounting." In D. Bradford, ed., Tax Policy and the Economy. Vol.5. Cambridge, MA: MIT Press.

Aydede (2006) "Aggregate Consumption Function and Public Social Security: The Fist TimeSeries Study for a Developing Country, Turkey. Applied Economics. Forthcoming.

Aydede (2006) "Social Security, Intergenerational Transfers, and Saving: New Evidence from an Emerging Country." NFI Working Paper. No: 2007-WP-16.

Barro, R. (1978). The Impact of Social Security on Private Saving: Evidence from New the US Time Series, American Enterprise Institute 199.

Barro, R. (1978). The Impact of Social Security on Private Saving: Evidence from New the US Time Series, American Enterprise Institute, AIE Studies 199.

Barro, R. (1989). The Ricardian Approach to Budget Deficits, Journal of Economic Perspectives, vol. 3(2).

Boskin, M, Kotlikoff, L., Puffert, D., Shoven, J. (1985). Social Security: A Financial Appraisal Across and Within Generations. National Tax Journal, Vol. XL.

Brook, A. and Whitehouse, E. (2007). The Turkish Pension System: Further Reforms to Help Solve the Informality Problem. Working Paper, No. 529. OECD Economic Department.

Bulutay, T. (1995) Employment, Unemployment and Wages in Turkey, ILO.

CBO Memorandum, (1998) Congressional Budget Office.

Engen, E. and Gale, W. (1997). Effects of Social Security Reform on Private and National Saving. Social Security Reform: Links to Saving, Investment and Growth: Conference Proceedings, Federal Reserve Bank of Boston. June 1997.

Esposito, L. (1978). Effect of Social Security on Saving: Review of Studies Using U.S. Time- 
Series Data. Social Security Bulletin, May 1978.

Eugene, S. and Bakija, J. (1994). Retooling Social Security for the 21 st Century: Right Ways and Wrong Ways to Reform. Washington, DC: Urban Institute Press.

Feldstein, M. (1974), Social Security, Induced Retirement, and Aggregate Capital Accumulation. Journal of Political Economy. Vol.82, No.5.

Feldstein, M. (1982). Social Security and Private Saving: Reply. Journal of Political Economy. Vol.90, No.3.

Feldstein, M. and Liebman, J., Ed., (2002). "The Distributional Aspects of Social Security and Social Security Reform." NBER. The University of Chicago Press.

Gruber, J. (2007). Public Finance and Public Policy. $2^{\text {nd }}$ Ed. Worth Publishers.

International Labor Organization (ILO), (1996). "Social Security and Health Insurance Reform Project, Social Security Confidential Final Report”, ILO, Geneva, March 1996.

IMF Report (2000) Turkey: Selected Issues and Statistical Appendix, IMF Staff Country Report No. 00/14.

Leimer, D.R. and Lesnoy, S.D. (1980). Social Security and Private Saving: A Reexamination of the Time-Series Evidence Using Alternative Social Security Wealth Variables. Social Security Administration, Working Paper No.19.

Leimer, D.R. and Lesnoy, S.D. (1982), Social Security and Private Saving: New Time-Series Evidence. Journal of Political Economy. Vol.90, No.3.

Magnussen, Kunt A. (1994). Old-Age Pensions, Retirement Behavior and Personal Saving: A Discussion of the Literature. Statistics Norway, Social and Economic Studies.

Meguire, P. (1998), Comment: Social Security and Private Savings, National Tax Journal.

Meyer, C., and Wolff, N. (1987). Intercohort and Intracohort Redistribution under Social Security. In "Social Security: A Critique of Radical Reform Proposals" edited by Meyer, C. Lexington Books.

Ministry of Labor and Social Security, (July 29, 2004). "Proposal for Reform in the Social Security System.” (Draft Text).

OECD (2005). Pensions at a Glance. Public Policies across OECD Countries. Paris

TUSIAD Report (2004). Turk Emeklilik Sisteminde Reform (Reform in Turkish Pension System). Yayin No. TUSIAD-T/2004-11/382. 
The World Bank Report (2000). Turkey Country Economic Memorandum Structural Reforms for Sustainable Growth. Report No. 20657-TU. 
Table 8: Covered Employment

\begin{tabular}{|c|c|c|c|c|c|c|c|c|}
\hline & \multicolumn{5}{|c|}{ ACTIVE INSURED } & \multicolumn{3}{|c|}{ COVERED EMPLOYMENT } \\
\hline & Employment & Male \% & Total & Male & Female & Male & Female & Total \\
\hline 1970 & $13,033,977$ & $63 \%$ & $2,172,330$ & $1,794,824$ & 377,506 & $22 \%$ & $8 \%$ & $17 \%$ \\
\hline 1971 & $13,264,658$ & $63 \%$ & $2,319,417$ & $1,925,861$ & 393,556 & $23 \%$ & $8 \%$ & $17 \%$ \\
\hline 1972 & $13,643,808$ & $63 \%$ & $2,694,212$ & $2,256,835$ & 437,377 & $26 \%$ & $9 \%$ & $20 \%$ \\
\hline 1973 & $13,908,917$ & $63 \%$ & $3,444,371$ & $2,970,794$ & 473,577 & $34 \%$ & $9 \%$ & $25 \%$ \\
\hline 1974 & $14,206,803$ & $63 \%$ & $3,698,895$ & $3,185,150$ & 513,745 & $36 \%$ & $10 \%$ & $26 \%$ \\
\hline 1975 & $14,386,813$ & $65 \%$ & $3,779,893$ & $3,258,062$ & 521,831 & $35 \%$ & $10 \%$ & $26 \%$ \\
\hline 1976 & $14,593,921$ & $65 \%$ & $4,066,968$ & $3,495,935$ & 571,033 & $37 \%$ & $11 \%$ & $28 \%$ \\
\hline 1977 & $15,070,207$ & $65 \%$ & $4,333,854$ & $3,735,129$ & 598,725 & $38 \%$ & $11 \%$ & $29 \%$ \\
\hline 1978 & $15,276,030$ & $65 \%$ & $4,415,401$ & $3,817,970$ & 597,431 & $38 \%$ & $11 \%$ & $29 \%$ \\
\hline 1979 & $15,505,451$ & $65 \%$ & $4,522,423$ & $3,879,174$ & 643,249 & $38 \%$ & $12 \%$ & $29 \%$ \\
\hline 1980 & $15,702,127$ & $65 \%$ & $4,708,044$ & $4,018,778$ & 689,266 & $39 \%$ & $12 \%$ & $30 \%$ \\
\hline 1981 & $15,839,014$ & $65 \%$ & $4,873,339$ & $4,131,249$ & 742,090 & $40 \%$ & $13 \%$ & $31 \%$ \\
\hline 1982 & $16,005,942$ & $65 \%$ & $4,935,697$ & $4,194,060$ & 741,637 & $40 \%$ & $13 \%$ & $31 \%$ \\
\hline 1983 & $16,169,270$ & $65 \%$ & $5,161,151$ & $4,398,315$ & 762,836 & $42 \%$ & $13 \%$ & $32 \%$ \\
\hline 1984 & $16,419,342$ & $65 \%$ & $5,485,719$ & $4,678,328$ & 807,391 & $44 \%$ & $14 \%$ & $33 \%$ \\
\hline 1985 & $16,699,204$ & $65 \%$ & $5,890,253$ & $5,048,532$ & 841,721 & $46 \%$ & $15 \%$ & $35 \%$ \\
\hline 1986 & $17,009,503$ & $65 \%$ & $6,472,816$ & $5,239,652$ & $1,233,164$ & $47 \%$ & $21 \%$ & $38 \%$ \\
\hline 1987 & $17,401,735$ & $65 \%$ & $6,895,530$ & $5,937,750$ & 957,780 & $52 \%$ & $16 \%$ & $40 \%$ \\
\hline 1988 & $17,754,000$ & $71 \%$ & $7,322,060$ & $6,293,562$ & $1,028,498$ & $50 \%$ & $20 \%$ & $41 \%$ \\
\hline 1989 & $18,222,000$ & $69 \%$ & $7,692,484$ & $6,593,530$ & $1,098,954$ & $53 \%$ & $19 \%$ & $42 \%$ \\
\hline 1990 & $18,539,000$ & $70 \%$ & $7,990,454$ & $6,825,393$ & $1,165,061$ & $53 \%$ & $21 \%$ & $43 \%$ \\
\hline 1991 & $19,289,000$ & $69 \%$ & $8,201,767$ & $7,030,647$ & $1,171,120$ & $52 \%$ & $20 \%$ & $43 \%$ \\
\hline 1992 & $19,459,000$ & $70 \%$ & $8,727,634$ & $7,440,548$ & $1,287,086$ & $54 \%$ & $22 \%$ & $45 \%$ \\
\hline 1993 & $18,501,000$ & $74 \%$ & $8,993,561$ & $7,678,481$ & $1,315,080$ & $56 \%$ & $28 \%$ & $49 \%$ \\
\hline 1994 & $20,006,000$ & $71 \%$ & $9,083,046$ & $7,720,429$ & $1,362,617$ & $54 \%$ & $23 \%$ & $45 \%$ \\
\hline 1995 & $20,585,000$ & $71 \%$ & $9,284,849$ & $7,961,193$ & $1,323,656$ & $54 \%$ & $22 \%$ & $45 \%$ \\
\hline 1996 & $21,194,000$ & $71 \%$ & $9,554,743$ & $8,086,778$ & $1,467,965$ & $54 \%$ & $24 \%$ & $45 \%$ \\
\hline 1997 & $21,201,000$ & $73 \%$ & $10,187,024$ & $8,632,350$ & $1,554,674$ & $56 \%$ & $27 \%$ & $48 \%$ \\
\hline 1998 & $21,778,000$ & $72 \%$ & $10,845,817$ & $9,190,931$ & $1,654,886$ & $59 \%$ & $27 \%$ & $50 \%$ \\
\hline 1999 & $22,048,000$ & $71 \%$ & $10,460,794$ & $8,363,568$ & $2,097,226$ & $53 \%$ & $33 \%$ & $47 \%$ \\
\hline 2000 & $21,581,000$ & $73 \%$ & $10,994,287$ & $8,812,562$ & $2,181,725$ & $56 \%$ & $38 \%$ & $51 \%$ \\
\hline 2001 & $21,525,000$ & $72 \%$ & $10,674,982$ & $8,542,334$ & $2,132,648$ & $55 \%$ & $36 \%$ & $50 \%$ \\
\hline 2002 & $21,351,000$ & $71 \%$ & $11,137,196$ & $8,911,761$ & $2,225,435$ & $59 \%$ & $36 \%$ & $52 \%$ \\
\hline 2003 & $21,148,000$ & $72 \%$ & $11,663,428$ & $9,267,583$ & $2,395,845$ & $61 \%$ & $41 \%$ & $55 \%$ \\
\hline
\end{tabular}

Sources: Collected statistics from SSK, Emekli Sandigi, Bag-Kur 


\begin{tabular}{|c|c|c|c|c|c|c|c|c|c|c|c|c|c|c|c|}
\hline \multicolumn{3}{|c|}{ SSK } & \multicolumn{3}{|c|}{ ES } & \multicolumn{3}{|c|}{ BK } & \multicolumn{3}{|c|}{ Total } & \multicolumn{3}{|c|}{ AE } & \multirow[b]{2}{*}{$\mathbf{T}$} \\
\hline & $\mathbf{M}$ & $F$ & $\mathbf{T}$ & $\mathbf{M}$ & $\mathbf{F}$ & $\mathbf{T}$ & $\mathbf{M}$ & $F$ & $\mathbf{T}$ & $\mathbf{M}$ & $F$ & $\mathbf{T}$ & $\mathbf{M}$ & $F$ & \\
\hline 1970 & 2.36 & 1.65 & 2.25 & 3.09 & 2.16 & 2.83 & - & - & - & 2.81 & 1.97 & 2.61 & 2.81 & 1.97 & 2.61 \\
\hline 1971 & 1.56 & 1.09 & 1.49 & 4.31 & 3.02 & 3.94 & - & - & - & 3.05 & 2.14 & 2.85 & 3.05 & 2.14 & 2.85 \\
\hline 1972 & 1.46 & 1.02 & 1.40 & 4.29 & 3.00 & 3.92 & - & - & - & 3.06 & 2.14 & 2.85 & 3.00 & 2.10 & 2.79 \\
\hline 1973 & 1.42 & 1.00 & 1.36 & 4.01 & 2.81 & 3.67 & 1.81 & 1.27 & 1.75 & 2.83 & 1.98 & 2.64 & 2.94 & 2.06 & 2.74 \\
\hline 1974 & 1.23 & 0.86 & 1.17 & 2.65 & 1.86 & 2.42 & 3.69 & 2.58 & 3.55 & 2.03 & 1.42 & 1.89 & 2.49 & 1.74 & 2.32 \\
\hline 1975 & 1.69 & 1.18 & 1.61 & 2.75 & 1.92 & 2.51 & 0.97 & 0.68 & 0.93 & 2.27 & 1.59 & 2.12 & 2.35 & 1.65 & 2.19 \\
\hline 1976 & 1.38 & 0.97 & 1.32 & 2.77 & 1.94 & 2.53 & 2.38 & 1.67 & 2.29 & 2.10 & 1.47 & 1.96 & 2.13 & 1.49 & 1.98 \\
\hline 1977 & 1.37 & 0.96 & 1.30 & 2.62 & 1.83 & 2.39 & 0.06 & 0.04 & 0.06 & 1.92 & 1.35 & 1.80 & 2.06 & 1.44 & 1.92 \\
\hline 1978 & 1.37 & 0.96 & 1.31 & 2.14 & 1.50 & 1.96 & 0.74 & 0.52 & 0.71 & 1.70 & 1.19 & 1.59 & 1.86 & 1.30 & 1.74 \\
\hline 1979 & 1.04 & 0.73 & 0.99 & 1.69 & 1.18 & 1.54 & 0.61 & 0.43 & 0.59 & 1.28 & 0.90 & 1.21 & 1.55 & 1.08 & 1.45 \\
\hline 1980 & 0.91 & 0.64 & 0.88 & 1.32 & 0.92 & 1.21 & 0.44 & 0.31 & 0.42 & 1.02 & 0.71 & 0.96 & 1.26 & 0.88 & 1.18 \\
\hline 1981 & 0.94 & 0.66 & 0.90 & 1.26 & 0.88 & 1.15 & 0.50 & 0.35 & 0.48 & 1.00 & 0.70 & 0.94 & 1.08 & 0.75 & 1.01 \\
\hline 1982 & 0.97 & 0.68 & 0.93 & 1.31 & 0.92 & 1.20 & 0.47 & 0.33 & 0.45 & 1.03 & 0.72 & 0.97 & 1.02 & 0.71 & 0.96 \\
\hline 1983 & 0.94 & 0.66 & 0.90 & 1.27 & 0.89 & 1.16 & 0.62 & 0.44 & 0.60 & 1.01 & 0.70 & 0.95 & 1.01 & 0.71 & 0.96 \\
\hline 1984 & 0.80 & 0.56 & 0.77 & 0.99 & 0.69 & 0.90 & 0.53 & 0.37 & 0.51 & 0.83 & 0.58 & 0.78 & 0.92 & 0.65 & 0.87 \\
\hline 1985 & 0.70 & 0.49 & 0.67 & 0.97 & 0.68 & 0.88 & 0.52 & 0.36 & 0.50 & 0.76 & 0.53 & 0.72 & 0.84 & 0.59 & 0.79 \\
\hline 1986 & 0.59 & 0.41 & 0.56 & 0.90 & 0.63 & 0.82 & 0.46 & 0.33 & 0.45 & 0.66 & 0.46 & 0.63 & 0.73 & 0.51 & 0.69 \\
\hline 1987 & 0.49 & 0.34 & 0.47 & 0.73 & 0.51 & 0.66 & 0.27 & 0.19 & 0.26 & 0.52 & 0.37 & 0.50 & 0.62 & 0.43 & 0.58 \\
\hline 1988 & 0.65 & 0.45 & 0.62 & 0.69 & 0.48 & 0.63 & 0.32 & 0.23 & 0.31 & 0.60 & 0.42 & 0.57 & 0.60 & 0.42 & 0.56 \\
\hline 1989 & 0.57 & 0.40 & 0.54 & 1.17 & 0.82 & 1.07 & 0.33 & 0.23 & 0.32 & 0.68 & 0.48 & 0.65 & 0.62 & 0.44 & 0.59 \\
\hline 1990 & 0.52 & 0.36 & 0.50 & 1.33 & 0.93 & 1.22 & 0.34 & 0.24 & 0.33 & 0.70 & 0.49 & 0.66 & 0.67 & 0.47 & 0.64 \\
\hline 1991 & 0.56 & 0.40 & 0.54 & 1.29 & 0.90 & 1.18 & 0.30 & 0.21 & 0.29 & 0.69 & 0.49 & 0.66 & 0.69 & 0.49 & 0.66 \\
\hline 1992 & 0.55 & 0.39 & 0.53 & 1.27 & 0.89 & 1.16 & 0.39 & 0.27 & 0.37 & 0.70 & 0.49 & 0.67 & 0.70 & 0.49 & 0.66 \\
\hline 1993 & 0.49 & 0.34 & 0.47 & 1.11 & 0.78 & 1.02 & 0.37 & 0.26 & 0.35 & 0.62 & 0.43 & 0.59 & 0.66 & 0.46 & 0.63 \\
\hline 1994 & 0.37 & 0.26 & 0.35 & 0.87 & 0.61 & 0.80 & 0.33 & 0.23 & 0.32 & 0.49 & 0.34 & 0.46 & 0.57 & 0.40 & 0.54 \\
\hline 1995 & 0.29 & 0.20 & 0.27 & 1.10 & 0.77 & 1.00 & 0.29 & 0.20 & 0.28 & 0.46 & 0.32 & 0.44 & 0.51 & 0.35 & 0.48 \\
\hline 1996 & 0.60 & 0.42 & 0.57 & 1.41 & 0.98 & 1.28 & 0.39 & 0.27 & 0.38 & 0.73 & 0.51 & 0.69 & 0.60 & 0.42 & 0.57 \\
\hline 1997 & 0.78 & 0.54 & 0.74 & 1.47 & 1.03 & 1.35 & 0.41 & 0.28 & 0.39 & 0.85 & 0.60 & 0.81 & 0.72 & 0.51 & 0.69 \\
\hline 1998 & 0.80 & 0.56 & 0.76 & 1.43 & 1.00 & 1.31 & 0.63 & 0.44 & 0.61 & 0.90 & 0.63 & 0.85 & 0.85 & 0.59 & 0.80 \\
\hline 1999 & 0.87 & 0.61 & 0.82 & 1.61 & 1.13 & 1.48 & 0.76 & 0.53 & 0.74 & 1.00 & 0.70 & 0.95 & 0.94 & 0.66 & 0.89 \\
\hline 2000 & 0.78 & 0.55 & 0.74 & 1.46 & 1.02 & 1.33 & 0.71 & 0.50 & 0.69 & 0.91 & 0.64 & 0.86 & 0.93 & 0.65 & 0.88 \\
\hline 2001 & 0.80 & 0.56 & 0.76 & 1.48 & 1.04 & 1.35 & 0.68 & 0.48 & 0.66 & 0.92 & 0.64 & 0.87 & 0.94 & 0.66 & 0.89 \\
\hline 2002 & 0.86 & 0.60 & 0.82 & 1.59 & 1.11 & 1.45 & 0.80 & 0.56 & 0.77 & 1.00 & 0.70 & 0.94 & 0.96 & 0.67 & 0.90 \\
\hline 2003 & 0.87 & 0.61 & 0.82 & 1.61 & 1.12 & 1.47 & 1.01 & 0.70 & 0.97 & 1.04 & 0.73 & 0.99 & 1.00 & 0.70 & 0.95 \\
\hline & 34 & 34 & 34 & 34 & 34 & 34 & 31 & 31 & 31 & 34 & 34 & 34 & & & $1970-2003$ \\
\hline & 0.93 & 0.65 & 0.89 & 1.76 & 1.23 & 1.61 & 0.71 & 0.50 & 0.69 & 1.24 & 0.87 & 1.17 & & & \\
\hline
\end{tabular}

\footnotetext{
${ }^{51}$ Social Security Institution (Sosyal Sigortalar Kurumu -- SSK) for wage earners, Bag-Kur (BK) for self-employed people, and the Pension Fund (Emekli Sandigi -- ES) for civil servants. AE denotes, the second perception methods with the weights of $50 \%$ for the first year and $25 \%$ for the last two years each.
} 
Table 10: Tax Factors ${ }^{52}$

\begin{tabular}{|c|c|c|c|c|c|c|c|c|c|c|c|c|c|c|c|}
\hline \multicolumn{3}{|c|}{ SSK } & \multicolumn{3}{|c|}{ ES } & \multicolumn{3}{|c|}{ BK } & \multicolumn{3}{|c|}{ Total } & \multicolumn{3}{|c|}{$A E$} & \multirow[b]{2}{*}{$\mathbf{T}$} \\
\hline & $\mathbf{M}$ & $F$ & $T$ & M & $\mathbf{F}$ & $\mathbf{T}$ & $\mathbf{M}$ & $\mathbf{F}$ & $T$ & $\mathbf{M}$ & $\mathbf{F}$ & $\mathbf{T}$ & M & $\mathbf{F}$ & \\
\hline 1970 & 0.30 & 0.21 & 0.30 & 0.51 & 0.36 & 0.46 & - & - & - & 0.38 & 0.27 & 0.36 & 0.38 & 0.27 & 0.36 \\
\hline 1971 & 0.26 & 0.19 & 0.26 & 0.92 & 0.65 & 0.84 & - & - & - & 0.51 & 0.36 & 0.48 & 0.51 & 0.36 & 0.48 \\
\hline 1972 & 0.25 & 0.17 & 0.24 & 0.81 & 0.56 & 0.73 & 0.06 & 0.04 & 0.06 & 0.42 & 0.29 & 0.40 & 0.43 & 0.30 & 0.41 \\
\hline 1973 & 0.28 & 0.20 & 0.27 & 0.71 & 0.50 & 0.65 & 0.11 & 0.08 & 0.11 & 0.36 & 0.25 & 0.34 & 0.41 & 0.29 & 0.39 \\
\hline 1974 & 0.27 & 0.19 & 0.26 & 0.73 & 0.51 & 0.66 & 0.08 & 0.06 & 0.08 & 0.35 & 0.25 & 0.34 & 0.37 & 0.26 & 0.35 \\
\hline 1975 & 0.33 & 0.23 & 0.32 & 0.86 & 0.60 & 0.78 & 0.07 & 0.05 & 0.07 & 0.42 & 0.29 & 0.40 & 0.39 & 0.27 & 0.37 \\
\hline 1976 & 0.35 & 0.25 & 0.34 & 0.65 & 0.46 & 0.59 & 0.06 & 0.04 & 0.06 & 0.37 & 0.26 & 0.35 & 0.38 & 0.26 & 0.36 \\
\hline 1977 & 0.36 & 0.25 & 0.35 & 0.64 & 0.45 & 0.58 & 0.06 & 0.04 & 0.06 & 0.37 & 0.26 & 0.35 & 0.38 & 0.27 & 0.36 \\
\hline 1978 & 0.36 & 0.25 & 0.35 & 0.56 & 0.39 & 0.51 & 0.04 & 0.03 & 0.04 & 0.34 & 0.24 & 0.33 & 0.35 & 0.25 & 0.34 \\
\hline 1979 & 0.29 & 0.21 & 0.29 & 0.52 & 0.36 & 0.47 & 0.05 & 0.03 & 0.05 & 0.29 & 0.21 & 0.28 & 0.32 & 0.23 & 0.31 \\
\hline 1980 & 0.22 & 0.16 & 0.22 & 0.40 & 0.28 & 0.36 & 0.07 & 0.05 & 0.07 & 0.23 & 0.16 & 0.22 & 0.28 & 0.19 & 0.26 \\
\hline 1981 & 0.29 & 0.21 & 0.29 & 0.38 & 0.27 & 0.35 & 0.08 & 0.06 & 0.08 & 0.27 & 0.19 & 0.25 & 0.27 & 0.19 & 0.25 \\
\hline 1982 & 0.30 & 0.21 & 0.29 & 0.42 & 0.29 & 0.38 & 0.09 & 0.06 & 0.09 & 0.28 & 0.19 & 0.27 & 0.26 & 0.19 & 0.25 \\
\hline 1983 & 0.33 & 0.23 & 0.32 & 0.44 & 0.31 & 0.40 & 0.08 & 0.06 & 0.08 & 0.29 & 0.20 & 0.28 & 0.28 & 0.20 & 0.27 \\
\hline 1984 & 0.30 & 0.21 & 0.29 & 0.36 & 0.25 & 0.33 & 0.07 & 0.05 & 0.06 & 0.25 & 0.17 & 0.24 & 0.26 & 0.19 & 0.25 \\
\hline 1985 & 0.27 & 0.19 & 0.27 & 0.36 & 0.25 & 0.33 & 0.07 & 0.05 & 0.07 & 0.23 & 0.16 & 0.22 & 0.25 & 0.17 & 0.24 \\
\hline 1986 & 0.26 & 0.18 & 0.25 & 0.36 & 0.25 & 0.33 & 0.05 & 0.03 & 0.04 & 0.21 & 0.15 & 0.20 & 0.22 & 0.16 & 0.21 \\
\hline 1987 & 0.34 & 0.24 & 0.33 & 0.28 & 0.20 & 0.26 & 0.03 & 0.02 & 0.03 & 0.22 & 0.15 & 0.21 & 0.22 & 0.15 & 0.21 \\
\hline 1988 & 0.30 & 0.21 & 0.29 & 0.31 & 0.21 & 0.28 & 0.03 & 0.02 & 0.03 & 0.21 & 0.14 & 0.20 & 0.21 & 0.15 & 0.20 \\
\hline 1989 & 0.30 & 0.21 & 0.29 & 0.53 & 0.37 & 0.48 & 0.03 & 0.02 & 0.03 & 0.24 & 0.17 & 0.23 & 0.23 & 0.16 & 0.22 \\
\hline 1990 & 0.32 & 0.22 & 0.31 & 0.66 & 0.46 & 0.60 & 0.03 & 0.02 & 0.03 & 0.28 & 0.19 & 0.27 & 0.25 & 0.18 & 0.24 \\
\hline 1991 & 0.35 & 0.25 & 0.34 & 0.69 & 0.48 & 0.63 & 0.03 & 0.02 & 0.03 & 0.30 & 0.21 & 0.29 & 0.28 & 0.20 & 0.27 \\
\hline 1992 & 0.31 & 0.21 & 0.30 & 0.64 & 0.44 & 0.58 & 0.04 & 0.03 & 0.04 & 0.28 & 0.20 & 0.27 & 0.29 & 0.20 & 0.27 \\
\hline 1993 & 0.26 & 0.18 & 0.25 & 0.53 & 0.37 & 0.48 & 0.03 & 0.02 & 0.03 & 0.24 & 0.17 & 0.23 & 0.27 & 0.19 & 0.25 \\
\hline 1994 & 0.19 & 0.13 & 0.18 & 0.49 & 0.34 & 0.44 & 0.03 & 0.02 & 0.03 & 0.20 & 0.14 & 0.19 & 0.23 & 0.16 & 0.22 \\
\hline 1995 & 0.13 & 0.09 & 0.12 & 0.55 & 0.38 & 0.49 & 0.03 & 0.02 & 0.03 & 0.18 & 0.13 & 0.17 & 0.20 & 0.14 & 0.19 \\
\hline 1996 & 0.20 & 0.14 & 0.19 & 0.63 & 0.44 & 0.57 & 0.04 & 0.03 & 0.04 & 0.24 & 0.17 & 0.23 & 0.21 & 0.15 & 0.21 \\
\hline 1997 & 0.23 & 0.16 & 0.22 & 0.69 & 0.48 & 0.62 & 0.06 & 0.04 & 0.06 & 0.27 & 0.19 & 0.25 & 0.24 & 0.17 & 0.23 \\
\hline 1998 & 0.21 & 0.15 & 0.20 & 0.69 & 0.48 & 0.62 & 0.05 & 0.04 & 0.05 & 0.25 & 0.18 & 0.24 & 0.25 & 0.18 & 0.24 \\
\hline 1999 & 0.27 & 0.19 & 0.26 & 0.72 & 0.51 & 0.65 & 0.06 & 0.04 & 0.06 & 0.30 & 0.21 & 0.28 & 0.28 & 0.20 & 0.26 \\
\hline 2000 & 0.33 & 0.23 & 0.31 & 0.67 & 0.47 & 0.60 & 0.07 & 0.05 & 0.07 & 0.31 & 0.22 & 0.29 & 0.29 & 0.20 & 0.28 \\
\hline 2001 & 0.36 & 0.25 & 0.34 & 0.67 & 0.47 & 0.60 & 0.08 & 0.06 & 0.08 & 0.33 & 0.23 & 0.31 & 0.32 & 0.22 & 0.30 \\
\hline 2002 & 0.35 & 0.25 & 0.33 & 0.70 & 0.49 & 0.63 & 0.10 & 0.07 & 0.09 & 0.34 & 0.24 & 0.32 & 0.33 & 0.23 & 0.31 \\
\hline 2003 & 0.38 & 0.26 & 0.35 & 0.74 & 0.52 & 0.67 & 0.11 & 0.07 & 0.10 & 0.37 & 0.26 & 0.35 & 0.35 & 0.25 & 0.33 \\
\hline ount & 34 & 34 & 34 & 34 & 34 & 34 & 32 & 32 & 32 & 34 & 34 & 34 & & & $1970-2003$ \\
\hline Mean & 0.29 & 0.20 & 0.28 & 0.58 & 0.41 & 0.53 & 0.06 & 0.04 & 0.06 & 0.30 & 0.21 & 0.28 & & & \\
\hline
\end{tabular}

\footnotetext{
${ }^{52}$ Social Security Institution (Sosyal Sigortalar Kurumu -- SSK) for wage earners, Bag-Kur (BK) for self-employed people, and the Pension Fund (Emekli Sandigi -- ES) for civil servants. AE denotes, the second perception methods with the weights of $50 \%$ for the first year and $25 \%$ for the last two years each.
} 
Table 11: SSW Series ${ }^{53}$ (with different assumptions)

\begin{tabular}{|c|c|c|c|c|c|c|c|c|c|c|}
\hline & $\begin{array}{c}\text { d } \\
\text { Factors }\end{array}$ & $\begin{array}{c}0.03 \\
\mathrm{cr}\end{array}$ & $\begin{array}{c}\text { d } \\
\text { Factors }\end{array}$ & $\begin{array}{c}0.03 \\
a v\end{array}$ & $\begin{array}{c}\text { d } \\
\text { Factors }\end{array}$ & $\begin{array}{c}0.03 \\
a e\end{array}$ & $\begin{array}{c}\text { d } \\
\text { Factors }\end{array}$ & $\begin{array}{c}0.05 \\
\mathrm{cr}\end{array}$ & $\begin{array}{c}\text { d } \\
\text { Factors }\end{array}$ & $\begin{array}{c}0.05 \\
a e\end{array}$ \\
\hline & SSWG & SSW & SSWG & SSW & SSWG & SSW & SSWG & SSW & SSWG & SSW \\
\hline 1970 & $1,538,760$ & $1,237,829$ & 750,028 & 506,317 & $1,538,760$ & $1,237,829$ & 918,216 & 684,551 & 918,216 & 684,551 \\
\hline 1971 & $1,853,718$ & $1,414,656$ & 861,335 & 603,818 & $1,853,718$ & $1,414,656$ & $1,113,406$ & 772,483 & $1,113,406$ & 772,483 \\
\hline 1972 & $2,292,276$ & $1,831,641$ & $1,059,521$ & 740,907 & $2,249,680$ & $1,787,542$ & $1,374,583$ & $1,016,903$ & $1,350,122$ & 991,277 \\
\hline 1973 & $2,591,300$ & $2,117,187$ & $1,257,458$ & 864,126 & $2,685,384$ & $2,142,049$ & $1,545,950$ & $1,177,791$ & $1,599,990$ & $1,178,079$ \\
\hline 1974 & $2,002,789$ & $1,506,492$ & $1,291,673$ & 870,015 & $2,413,238$ & $1,889,419$ & $1,197,103$ & 811,719 & $1,432,855$ & $1,026,099$ \\
\hline 1975 & $2,236,259$ & $1,726,031$ & $1,315,737$ & 882,243 & $2,307,708$ & $1,769,186$ & $1,325,961$ & 930,264 & $1,366,532$ & 948,893 \\
\hline 1976 & $2,323,808$ & $1,756,546$ & $1,468,598$ & 986,649 & $2,348,358$ & $1,749,640$ & $1,383,670$ & 943,742 & $1,397,610$ & 933,287 \\
\hline 1977 & $2,366,450$ & $1,748,615$ & $1,627,208$ & $1,102,292$ & $2,508,383$ & $1,856,288$ & $1,421,293$ & 942,145 & $1,501,888$ & 996,169 \\
\hline 1978 & $2,071,286$ & $1,467,960$ & $1,582,035$ & $1,069,445$ & $2,234,614$ & $1,597,832$ & $1,249,904$ & 782,007 & $1,342,648$ & 848,805 \\
\hline 1979 & $1,662,872$ & $1,038,514$ & $1,615,584$ & $1,085,125$ & $1,952,480$ & $1,293,500$ & $1,014,261$ & 530,053 & $1,178,707$ & 667,648 \\
\hline 1980 & $1,438,040$ & 763,872 & $1,701,377$ & $1,128,599$ & $1,718,052$ & $1,006,500$ & 882,282 & 360,344 & $1,041,085$ & 490,203 \\
\hline 1981 & $1,310,707$ & 702,571 & $1,565,555$ & $1,048,878$ & $1,390,194$ & 748,335 & 811,436 & 340,619 & 856,514 & 359,589 \\
\hline 1982 & $1,424,697$ & 795,018 & $1,655,857$ & $1,120,877$ & $1,412,824$ & 748,227 & 887,456 & 399,960 & 880,723 & 366,194 \\
\hline 1983 & $1,442,825$ & 793,914 & $1,707,867$ & $1,156,547$ & $1,447,783$ & 762,888 & 901,323 & 398,938 & 904,134 & 373,891 \\
\hline 1984 & $1,330,385$ & 473,489 & $1,849,264$ & $1,236,679$ & $1,450,014$ & 656,712 & 833,636 & 170,230 & 901,480 & 287,308 \\
\hline 1985 & $1,246,935$ & 482,981 & $1,865,051$ & $1,250,103$ & $1,347,129$ & 569,151 & 782,743 & 190,448 & 839,935 & 236,767 \\
\hline 1986 & $1,176,051$ & 366,237 & $1,974,595$ & $1,312,404$ & $1,266,389$ & 424,836 & 740,275 & 112,449 & 791,827 & 139,396 \\
\hline 1987 & $1,190,243$ & 221,957 & $2,463,057$ & $1,618,056$ & $1,358,668$ & 352,216 & 750,295 & (423) & 846,435 & 66,128 \\
\hline 1988 & $1,414,424$ & 627,432 & $2,601,326$ & $1,804,874$ & $1,408,903$ & 542,304 & 907,923 & 292,942 & 904,677 & 227,489 \\
\hline 1989 & $1,689,484$ & $1,043,496$ & $2,757,543$ & $1,938,640$ & $1,570,689$ & 810,806 & $1,090,033$ & 585,125 & $1,019,957$ & 426,028 \\
\hline 1990 & $1,984,882$ & $1,161,973$ & $3,164,679$ & $2,246,813$ & $1,921,580$ & $1,102,371$ & $1,288,880$ & 644,910 & $1,251,394$ & 610,318 \\
\hline 1991 & $2,077,414$ & $1,123,564$ & $3,314,198$ & $2,293,573$ & $2,075,380$ & $1,168,417$ & $1,334,771$ & 590,563 & $1,333,594$ & 625,968 \\
\hline 1992 & $2,343,007$ & $1,253,408$ & $3,705,528$ & $2,563,174$ & $2,335,932$ & $1,265,900$ & $1,504,815$ & 654,606 & $1,500,719$ & 665,805 \\
\hline 1993 & $2,348,538$ & $1,358,946$ & $4,116,223$ & $2,840,096$ & $2,459,535$ & $1,391,982$ & $1,514,234$ & 741,411 & $1,578,598$ & 744,892 \\
\hline 1994 & $1,679,146$ & 878,172 & $3,588,685$ & $2,448,664$ & $1,898,426$ & $1,041,595$ & $1,087,917$ & 462,376 & $1,214,937$ & 545,773 \\
\hline 1995 & $1,671,200$ & 802,779 & $3,749,300$ & $2,561,427$ & $1,798,141$ & 924,993 & $1,085,781$ & 406,967 & $1,159,350$ & 476,841 \\
\hline 1996 & $2,735,733$ & $1,894,410$ & $4,117,741$ & $2,904,011$ & $2,389,219$ & $1,533,536$ & $1,781,359$ & $1,123,897$ & $1,580,711$ & 912,027 \\
\hline 1997 & $3,617,608$ & $2,508,821$ & $4,790,526$ & $3,437,133$ & $3,226,278$ & $2,189,994$ & $2,363,515$ & $1,496,451$ & $2,136,814$ & $1,326,447$ \\
\hline 1998 & $4,256,076$ & $2,840,422$ & $5,417,815$ & $3,898,396$ & $4,069,528$ & $2,787,195$ & $2,771,161$ & $1,663,242$ & $2,662,975$ & $1,659,395$ \\
\hline 1999 & $4,410,336$ & $2,993,842$ & $5,131,022$ & $3,722,677$ & $4,219,029$ & $2,894,289$ & $2,923,774$ & $1,814,384$ & $2,811,871$ & $1,774,341$ \\
\hline 2000 & $4,104,165$ & $2,744,668$ & $5,132,662$ & $3,706,956$ & $4,170,868$ & $2,800,545$ & $2,726,582$ & $1,660,532$ & $2,765,649$ & $1,691,111$ \\
\hline 2001 & $3,946,646$ & $2,892,795$ & $4,875,007$ & $3,572,097$ & $4,002,618$ & $2,837,479$ & $2,645,874$ & $1,818,543$ & $2,678,741$ & $1,764,045$ \\
\hline 2002 & $4,270,969$ & $3,394,092$ & $4,966,195$ & $3,678,725$ & $4,146,627$ & $3,140,927$ & $2,861,526$ & $2,172,123$ & $2,788,260$ & $1,997,577$ \\
\hline 2003 & $4,835,109$ & $3,996,765$ & $5,454,142$ & $4,071,128$ & $4,699,809$ & $3,765,488$ & $3,239,580$ & $2,579,284$ & $3,159,574$ & $2,423,685$ \\
\hline
\end{tabular}

${ }^{53} a v$, average factors, is the first perception method; $a e$, adaptive expectations, is the second; and $c r$, current is the third. 
Table 12: SSW Series ${ }^{54}$ (with $d=3 \%, g$-annuities $=0 \%, g$-income $=2 \%$, and the current perception method)

\begin{tabular}{|c|c|c|c|c|}
\hline & $\begin{array}{c}\text { SSWG } \\
\text { Total }\end{array}$ & & & $\begin{array}{l}\text { SSTX } \\
\text { Total }\end{array}$ \\
\hline 0 & $54,350,527,270,554$ & $35,321,000$ & $1,538,760$ & $10,629,176,159,073$ \\
\hline & $67,132,406,937,214$ & $, 215,000$ & $1,853,718$ & $15,900,641,488,810$ \\
\hline 972 & $85,116,800,473,441$ & & $, 292,276$ & $17,104,28$ \\
\hline 73 & $98,658,575,257,819$ & & $, 591,300$ & 18,05 \\
\hline 974 & $78,182,880,531,866$ & & 2,789 & $19,373,970,7$ \\
\hline 975 & $89,508,490,160,736$ & & & $20,422,38$ \\
\hline 976 & $95,080,919,462,028$ & & 3,808 & $23,210,069,95$ \\
\hline 977 & $98,844,234$, & & & $25,806,3$ \\
\hline 978 & $88,321,712,321,793$ & & & $25,726,425,427,173$ \\
\hline 979 & 72, & & & ᄀᄀ००० \\
\hline 980 & 63,9 & & & 069 \\
\hline 981 & 59 , & & & 711 \\
\hline 982 & 66,5 & & & 086 \\
\hline 983 & 69 & & & 612 \\
\hline 1984 & 65,2 & & & ,275 \\
\hline 1985 & $62,728,296,4$ & & & 291 \\
\hline 1986 & $60,4 \varepsilon$ & & & $551,132,986,452$ \\
\hline 1987 & $62,560,386,5$ & & & $50,894,120,9$ \\
\hline 1988 & $75, \subseteq$ & & & 123 \\
\hline 1989 & 92 & & & 040 \\
\hline 1990 & 43 & & & 40 \\
\hline 1991 & 35 & & &, 514 \\
\hline 195 & 4 & & & 489 \\
\hline 1993 & 9 & & & 826 \\
\hline 1994 & 1. & & & 082 \\
\hline 1995 & 97 & & 0 & 367 \\
\hline 1996 & 24 & & & 538 \\
\hline 1997 & 94 & & 08 &, 920 \\
\hline 1998 & $277,262,042,246,312$ & & & $92,222,739,800,584$ \\
\hline & $292,422,906,663,681$ & & & $93,919,219,353,310$ \\
\hline 2000 & $276,903,910,265,064$ & & & $91,723,929,618,938$ \\
\hline & $270,810,986,790,403$ & & & $72,313,209,393,816$ \\
\hline 2002 & $97,929,985,831,085$ & $69,757,000$ & $4,270,969$ & $61,168,290,430,124$ \\
\hline 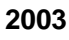 & $42,736,720,673,866$ & $70,885,000$ & $4,835,109$ & $59,426,004,874,410$ \\
\hline
\end{tabular}

$\begin{array}{rc}\text { Per Capita } & \text { Total } \\ 300,931 & 43,721,351,111,480 \\ 439,062 & 51,231,765,448,405 \\ 460,635 & 68,012,511,765,208 \\ 474,113 & 80,607,655,003,501 \\ 496,298 & 58,808,909,814,694 \\ 510,228 & 69,086,104,857,118 \\ 567,261 & 71,870,849,505,446 \\ 617,834 & 73,037,920,501,284 \\ 603,326 & 62,595,286,894,620 \\ 624,358 & 45,207,538,793,496 \\ 674,168 & 33,945,696,911,559 \\ 608,136 & 31,995,082,981,238 \\ 629,679 & 37,117,799,542,618 \\ 648,911 & 37,999,921,401,388 \\ 856,896 & 23,234,114,848,462 \\ 763,954 & 24,296,819,041,855 \\ 809,813 & 18,836,680,207,707 \\ 968,287 & 11,666,265,640,290 \\ 786,992 & 33,702,510,564,681 \\ 645,988 & 57,280,610,576,925 \\ 822,909 & 65,316,831,928,003 \\ 953,850 & 64,370,104,966,271 \\ 1,089,599 & 73,172,733,932,784 \\ 989,593 & 80,827,370,212,484 \\ 800,974 & 53,205,821,070,475 \\ 868,421 & 49,536,262,760,430 \\ 841,323 & 119,046,643,007,086 \\ 1,108,787 & 160,536,941,648,974 \\ 1,415,653 & 185,039,302,445,728 \\ 1,416,494 & 198,503,687,310,371 \\ 1,359,497 & 185,179,980,646,126 \\ 1,053,852 & 198,497,777,396,587 \\ 876,877 & 236,761,695,400,961 \\ 838,344 & 283,310,715,799,456\end{array}$

Per Capita

$1,237,829$

$1,414,656$

$1,831,641$

$2,117,187$

$1,506,492$

$1,726,031$

$1,756,546$

$1,748,615$

$1,467,960$

$1,038,514$

763,872

702,571

795,018

793,914

473,489

482,981

366,237

221,957

627,432

$1,043,496$

$1,161,973$

$1,123,564$

$1,253,408$

$1,358,946$

878,172

802,779

$1,894,410$

$2,508,821$

$2,840,422$

2,993,842

2,744,668

2,892,795

3,394,092

$3,996,765$

${ }^{54} \mathrm{~g}$ denotes the growth rate. 
Table 13: SSWG Series (with $d=3 \%$, g-annuities $=0 \%$, g-income $=2 \%$, and the current perception method)

\begin{tabular}{rcr} 
& Workers & \multicolumn{1}{c}{ Workers' Wives } \\
1970 & $42,389,956,317,351$ & $7,468,352,549,081$ \\
1971 & $51,526,390,882,588$ & $9,053,473,647,556$ \\
1972 & $65,469,345,492,228$ & $11,581,225,355,773$ \\
1973 & $76,590,626,375,903$ & $13,854,267,990,017$ \\
1974 & $60,431,874,061,241$ & $10,917,867,852,047$ \\
1975 & $68,932,927,885,622$ & $12,313,196,647,939$ \\
1976 & $72,520,160,694,066$ & $12,927,537,456,476$ \\
1977 & $73,802,017,614,673$ & $13,181,842,589,272$ \\
1978 & $65,139,903,002,534$ & $11,663,351,973,005$ \\
1979 & $51,899,592,751,310$ & $9,236,977,945,462$ \\
1980 & $45,151,548,555,259$ & $7,811,946,327,589$ \\
1981 & $41,081,403,161,972$ & $7,070,914,833,734$ \\
1982 & $44,906,373,865,005$ & $7,743,098,407,090$ \\
1983 & $46,341,500,296,538$ & $8,007,924,598,042$ \\
1984 & $43,399,080,489,901$ & $7,503,589,200,909$ \\
1985 & $41,885,577,283,786$ & $7,431,389,462,295$ \\
1986 & $40,338,892,978,600$ & $6,849,632,510,230$ \\
1987 & $41,233,940,146,710$ & $7,341,804,470,313$ \\
1988 & $50,013,961,759,123$ & $9,421,304,602,506$ \\
1989 & $60,533,164,662,732$ & $11,519,973,022,523$ \\
1990 & $71,970,119,328,821$ & $13,724,827,066,198$ \\
1991 & $75,738,451,206,243$ & $14,076,443,127,228$ \\
1992 & $87,543,052,642,385$ & $16,138,630,268,076$ \\
1993 & $88,537,154,517,579$ & $16,429,626,943,954$ \\
1994 & $63,285,646,852,325$ & $11,751,687,379,160$ \\
1995 & $63,212,896,329,304$ & $11,927,857,566,197$ \\
1996 & $104,482,469,889,783$ & $19,481,250,635,100$ \\
1997 & $139,141,619,899,724$ & $25,874,488,817,022$ \\
1998 & $168,606,859,497,856$ & $31,689,803,860,151$ \\
1999 & $169,345,094,927,582$ & $32,172,811,534,762$ \\
2000 & $159,030,812,113,033$ & $30,820,187,036,107$ \\
2001 & $151,096,290,487,080$ & $29,118,947,112,345$ \\
2002 & $167,925,273,466,549$ & $32,595,030,574,323$ \\
2003 & $194,779,474,899,311$ & $37,977,611,772,383$
\end{tabular}

\section{Retirees}

$2,275,950,120,748$

$3,545,807,357,182$

$4,757,599,167,616$

$5,013,237,263,135$

$4,112,023,949,165$

$5,189,742,693,017$

$6,015,631,144,730$

$7,399,215,642,072$

$7,248,496,251,241$

$7,123,477,761,366$

$7,138,897,199,395$

$7,568,982,701,048$

$9,380,528,598,757$

$9,800,762,299,501$

$9,543,027,095,771$

$8,987,825,199,910$

$8,926,179,880,086$

$9,437,970,398,145$

$11,553,340,217,862$

$14,302,510,006,869$

$17,333,636,443,012$

$19,674,935,842,793$

$22,112,405,382,576$

$23,093,143,784,927$

$17,787,845,753,447$

$18,438,980,638,338$

$32,710,744,161,058$

$44,759,722,228,645$

$52,821,671,958,977$ $62,309,674,491,934$ $59,715,998,731,710$ $61,820,770,802,245$ $66,838,136,162,187$ $74,752,535,034,733$
Retirees' Wives

$418,720,521,526$

$645,152,976,322$

$862,694,605,177$

$911,658,048,865$

$751,069,658,581$

$956,966,521,260$

$1,106,412,896,295$

$1,377,650,208,140$

$1,362,359,924,501$

$1,375,802,632,341$

$1,402,790,960,699$

$1,486,986,736,052$

$1,849,312,016,681$

$1,965,657,882,854$

$1,921,395,849,942$

$1,806,842,114,042$

$1,797,307,603,144$

$1,904,895,835,997$

$2,373,753,984,977$

$2,880,843,305,419$

$3,451,321,625,256$

$3,937,698,751,069$

$4,342,025,164,298$

$4,527,784,920,558$

$3,477,707,129,393$

$3,609,726,264,460$

$6,583,808,503,302$

$9,005,515,568,840$

$10,655,409,238,827$

$12,506,480,217,513$

$11,985,270,291,618$

$12,401,244,826,556$

$13,485,471,140,956$

$15,070,650,390,061$

\section{Disable}

$277,499,538,873$ $383,904,942,583$ $418,978,236,339$ $417,997,742,34$ $362,753,101,439$ $377,001,632,740$ $409,982,849,329$ $458,857,620,857$ $401,308,964,103$ $393,565,310,125$ $330,671,510,674$ $337,604,218,678$ $354,871,705,507$ $381,768,349,775$ $366,733,463,144$ $300,798,083,036$ $293,111,776,589$ $303,869,617,443$ $298,067,623,837$ $403,831,295,229$ $579,278,785,209$ $398,282,790,971$ $710,330,656,879$ $743,564,108,678$ $554,618,023,567$ $610,647,044,953$ $887,292,080,495$ $1,178,315,285,472$ $1,298,510,656,385$ $1,505,796,472,967$ $1,393,073,454,415$ $1,423,129,880,208$ $1,292,771,572,066$ $1,385,751,216,613$
Survivors

$1,520,048,222,976$ $1,977,677,130,984$ $2,026,957,616,308$ $1,870,787,837,559$ $1,607,291,909,392$ $1,738,654,780,158$ $2,101,194,421,132$ $2,624,650,737,315$ 2,506,292,206,408 $2,357,046,234,999$ $2,069,188,244,012$ $2,143,706,376,466$ 2,282,087,891,665 $2,561,782,978,289$ $2,548,163,865,070$ $2,315,864,321,077$ $2,282,688,445,509$ $2,337,906,120,566$ $2,315,357,365,500$ $3,100,498,772,192$ $4,515,018,239,647$ $5,191,290,705,482$ $5,935,961,507,060$ $6,355,093,014,613$ $4,876,904,839,665$ $5,322,946,613,544$ $7,770,637,653,886$ $11,527,438,176,191$ $12,189,787,034,117$ $14,583,049,018,922$ $13,958,568,638,182$ $14,950,603,681,969$ $15,793,302,915,005$ $18,770,697,360,765$
Total

$54,350,527,270,554$ $67,132,406,937,214$ $85,116,800,473,441$ $98,658,575,257,819$ $78,182,880,531,866$ $89,508,490,160,736$ $95,080,919,462,028$ $98,844,234,412,328$ $88,321,712,321,793$ $72,386,462,635,603$ $63,905,042,797,628$ $59,689,598,027,950$ $66,516,272,484,705$ $69,059,396,404,999$ $65,281,989,964,737$ $62,728,296,464,146$ $60,487,813,194,158$ $62,560,386,589,174$ $75,975,785,553,804$ $92,740,821,064,965$ $11,574,201,488,143$ $119,017,102,423,785$ $136,782,405,621,274$ $139,686,367,290,309$ $101,734,409,977,557$ $03,123,054,456,797$ $171,916,202,923,624$ $231,487,099,975,894$ $277,262,042,246,312$ $292,422,906,663,681$ $276,903,910,265,064$ $270,810,986,790,403$ $297,929,985,831,085$ $342,736,720,673,866$
Population Per Capita $35,321,000 \quad \mathbf{1 , 5 3 8 , 7 6 0}$ $36,215,000 \quad \mathbf{1 , 8 5 3 , 7 1 8}$ $37,132,000 \quad \mathbf{2 , 2 9 2 , 2 7 6}$ $38,073,000 \quad 2,591,300$ $39,037,000 \quad \mathbf{2 , 0 0 2 , 7 8 9}$ $40,026,000 \quad \mathbf{2 , 2 3 6 , 2 5 9}$ $40,916,000 \quad 2,323,808$ $41,769,000 \quad \mathbf{2 , 3 6 6 , 4 5 0}$ $42,641,000 \quad 2,071,286$ $43,531,000 \quad \mathbf{1 , 6 6 2 , 8 7 2}$ $44,439,000 \quad \mathbf{1 , 4 3 8 , 0 4 0}$ $45,540,000 \quad \mathbf{1 , 3 1 0 , 7 0 7}$ $46,688,000 \quad \mathbf{1 , 4 2 4 , 6 9 7}$ $47,864,000 \quad \mathbf{1 , 4 4 2 , 8 2 5}$ 49,070,000 $\mathbf{1 , 3 3 0 , 3 8 5}$ $50,306,000 \quad \mathbf{1 , 2 4 6 , 9 3 5}$ $51,433,000 \quad \mathbf{1 , 1 7 6 , 0 5 1}$ $52,561,000 \quad \mathbf{1 , 1 9 0 , 2 4 3}$ $53,715,000 \quad \mathbf{1 , 4 1 4 , 4 2 4}$ $54,893,000 \quad \mathbf{1 , 6 8 9 , 4 8 4}$ $56,212,000 \quad \mathbf{1 , 9 8 4 , 8 8 2}$ $57,291,000 \quad \mathbf{2 , 0 7 7 , 4 1 4}$ $58,379,000 \quad \mathbf{2 , 3 4 3 , 0 0 7}$ $59,478,000 \quad \mathbf{2 , 3 4 8 , 5 3 8}$ $60,587,000 \quad \mathbf{1 , 6 7 9 , 1 4 6}$ 61,706,000 1,671,200 $62,841,000 \quad 2,735,733$ $63,989,000 \quad \mathbf{3 , 6 1 7 , 6 0 8}$ $65,145,000 \quad \mathbf{4 , 2 5 6 , 0 7 6}$ $66,304,000 \quad \mathbf{4 , 4 1 0 , 3 3 6}$

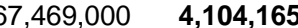
$68,618,000 \quad 3,946,646$ $69,757,000 \quad \mathbf{4 , 2 7 0 , 9 6 9}$ $70,885,000 \quad \mathbf{4 , 8 3 5 , 1 0 9}$ 